\title{
Tribological behaviour of sintered iron based self-lubricating composites
}

\author{
Jose Daniel Biasoli DE MELLO ${ }^{1,2,}$, Cristiano BINDER ${ }^{1}$, Gisele HAMMES ${ }^{1}$, Roberto BINDER ${ }^{3}$, Aloisio Nelmo \\ KLEIN $^{1}$ \\ ${ }^{1}$ Laboratorio de Materiais (LabMat), Universidade Federal de Santa Catarina, Florianópolis 88.040-900, SC, Brazil \\ ${ }^{2}$ Laboratorio de Tribologia e Materiais, Universidade Federal de Uberlândia, Uberlândia 38.400-902, MG, Brazil \\ ${ }^{3}$ Whirlpool, Embraco Unit, Joinville 89.219-900, SC, Brazil \\ Received: 09 June 2017 / Revised: 01 August 2017 / Accepted: 22 August 2017 \\ (C) The author(s) 2017. This article is published with open access at Springerlink.com
}

\begin{abstract}
This work is a review of previous works, presenting and discussing the most important results obtained by an ongoing research program towards the development of innovative, low-cost, self-lubricating composites with a low friction coefficient and high mechanical strength and wear resistance. Special emphasis is given to uniaxial die pressing of solid lubricant particles mixed with matrix powders and to metal injection moulding associated with in situ generation of solid lubricant particles. Initially, a microstructural model/ processing route (powder injection moulding followed by plasma-assisted debinding and sintering) produced a homogeneous dispersion of in situ generated solid lubricant particles. Micrometric nodules of graphite with diameter smaller than $20 \mu \mathrm{m}$ were formed, constituting a nanostructured stacking of graphite foils with nanometric thickness. Micro Raman analysis indicated that the graphite nodules were composed of turbostratic 2D graphite having highly misaligned graphene planes separated by large interlamellae distance. Large interplanar distance between the graphene foils and misalignment of these foils were confirmed by transmission electron microscopy and were, probably, the origin of the outstandingly low dry friction coefficient (0.04). The effect of sintering temperature, precursor content, metallic matrix composition and surface finish is also reported. Furthermore, the influence of a double-pressing/double-sintering (DPDS) technique on the tribological performance of self-lubricating uniaxially die-pressed hBN + graphite-Fe-Si-C-Mo composite is also investigated. Moreover, the tribological behaviour of die-pressed Fe-Si-C matrix composites containing 5, 7.5 and $10 \mathrm{wt} \%$ solid lubricants (hBN and graphite) added during the mixing step is analysed in terms of mechanical properties and wear mechanisms. Finally, the synergy between solid lubricant particles dispersed in a metallic matrix and fluid lubricants in a cooperative mixed lubrication regime is presented.
\end{abstract}

Keywords: tribological behaviour; powder metallurgy; iron based; self-lubricating; composites; turbostratic graphite

\section{Introduction}

Materials developed for friction and wear mitigation are commonly known as tribomaterials. These materials must primarily have mechanical and physical properties such as strength, stiffness, fatigue life, thermal expansion, and damping, in addition to the tribological properties [1]. However, the imperative need for miniaturized, more energy-efficient mechanical systems has imposed more severe tribological contacts, increasing the operational failure for conventional designs [2]. As a consequence, the tribology of critical contacts and new contact materials is the subject of extensive research [3-5]. Moreover, these interfaces must be

* Corresponding author: Jose Daniel Biasoli DE MELLO, E-mail: d.mello@ufsc.br, ltm-demello@ufu.br 
resistant to even more severe operating conditions owing to the tendency of using smaller clearances and increased speeds to achieve higher efficiency [6]. Moreover, the state of lubrication in many components is unknown and these components typically operate in the boundary and mixed lubrication regimes [7].

Hence, researchers are constantly exploring new materials and developing novel coatings. As a result, great strides have been achieved in recent years in the fabrication and diverse utilization of new tribomaterials and coatings that are capable of satisfying the multifunctional needs of more advanced mechanical systems [8].

In most common tribological applications, oils or greases are efficiently used to reduce friction and wear [9]. However, when service conditions become very severe (very high or very low temperatures, vacuum, radiation, extreme contact pressures or in very clean conditions such as foods and pharmaceuticals), oils and greases may decompose, oxidize, solidify, evaporate, or act as contaminants. In such cases, solid lubrication may be the only feasible choice for controlling friction and wear [6, 10-18]. A combination of solid and liquid lubrication is another possibility where positive synergistic effects on friction and wear may occur, particularly under mixed lubrication conditions [9].

Several inorganic materials (e.g., transition metals, graphite, hexagonal boron nitride, boric acid, etc.) can provide solid lubrication [12, 19-21]. Most of these materials, such as $\mathrm{MoS}_{2}, \mathrm{WS}_{2}, \mathrm{MoSe}_{2}$, graphite, and hexagonal boron nitride [18, 22-25], have a lamellar crystal structure, which is responsible for their lubricious properties. However, other materials can also exhibit good lubricity despite not having a layered structure, including soft metals, polytetrafluoroethylene (PTFE), polyimide, certain oxides and rare-earth fluorides, diamond and diamond-like carbons (DLC), and fullerenes [12, 20, 21].

Possible methods for applying solid lubricants include sprinkling, rubbing, burnishing, aerosol carrier, and bonding to a surface using adhesives; however, they have been progressively substituted by advanced vacuum deposition processes. However, in all those methods, a finite film thickness limits the lubricious effect. Some self-replenishment mechanism is necessary to ensure a long-lasting lubricious effect of a solid lubricant; however, this is very challenging to achieve [10].

In addition, nanoparticles of solid lubricants (nitrates [26, 27]; fullerene-like dichalcogenides [28-30]; metallic oxides such as $\mathrm{CuO}, \mathrm{ZnO}, \mathrm{ZrO}_{2}$, and $\mathrm{TiO}[31,32]$; titanium borate [33]; carbon nanotubes [34]; and graphene [35] are currently used as additives to liquid lubricants and greases to improve lubrication. However, incorporating nanoparticles into fluids and achieving good dispersion are not an easy task as the nanoparticles tend to agglomerate. To avoid such problems, some studies have shown that surface functionalization is necessary [36-38].

The production of self-lubricating composites appears to be a very encouraging solution $[22,23]$. Indeed, metallic matrix self-lubricating composites have been largely used in the industry to reduce wear and friction [10]. They contain a large amount of solid lubricant particles, around $15 \%$ to $40 \%$, which span from compounds such as $\mathrm{MoS}_{2}, \mathrm{WS}_{2}, \mathrm{MoSe}_{2}, \mathrm{NbS}_{2}, \mathrm{TaSe}_{2}, \mathrm{hBN}$, and $\mathrm{MoT}_{\mathrm{e} 2}$ to low-melting metals such as $\mathrm{Pb}, \mathrm{Sn}, \mathrm{Ag}$, and graphite to polymers such as PTFE [22-25].

There are many manufacturing routes for producing such composites, in polymeric, metallic, or even ceramic matrices [39-41]. For particle-reinforced metallic matrix composites, the synthesis methods are generally classified into vapour deposition techniques [42], solid state processing, and liquid state processing. Copper [43], nickel [44], and ferrous alloys [45, 46] are the materials most frequently used as metallic matrices. Iron-based materials contain iron as a prime constituent and play a significant role in engineering applications owing to their low cost, ease of manufacture, high strength, toughness, ductility, and availability [1].

Powder metallurgy (PM) techniques are especially suitable for the production of such composites. PM offers low cost for large-volume production, is very versatile for producing near-net-shape components, and results in tight dimensional tolerances. Therefore, it is highly competitive and attractive in the industry. In addition, PM exhibits great suitability for tailoring the microstructure according to the property and performance requirements of a given application. In recent years, the production of iron-based sintered 
tribomaterials has considerably increased at the expense of copper-based tribomaterials, owing to the lower cost and larger availability of iron powders, as well as their higher strength [47]. In the last decade, highperformance sintered iron-based self-lubricating composites were developed $[1,15,16,48-53]$ as a promising solution for combining a low friction coefficient with improved mechanical and wear resistance.

Sintered components have high porosity, which reduces the mechanical strength and load-bearing capacity when compared with fully dense materials $[54,55]$, but have the potential to store lubricants that can be released during use $[56,57]$. In addition, trapping of wear debris from sliding interfaces may be another important task achieved by the pores [58]; however, the behaviour depends on the imposed tribological system. It has been observed that pores can be beneficial in some systems and detrimental in others $[59,60]$.

In this context, the production of self-lubricating composites containing small amounts of solid lubricants incorporated into a continuous matrix and having a low friction coefficient combined with high mechanical strength and wear resistance appears to be a promising solution for controlling friction and wear in modern systems and points to an engineered microstructure. In this sense, we have recently proposed [14] a new microstructural model/processing route that can produce a homogeneous dispersion of in situ generated, discrete, solid lubricant particles in the volume of sintered composites. The high mechanical and tribological performances of the composites are a result of the combination of matrix mechanical properties [45] and structural parameters, such as the degree of continuity of the metallic matrix, the nature, the amount [61], and the lubricant particle size and distribution [62-64] and shape, which determine the mean free path between solid lubricant particles and the active area covered by each lubricant particle. Moreover, the success of self-lubricating composites depends on the capability of the solid lubricant particles to emerge from their embedded state in the matrix and spread evenly throughout [65-67], thus forming a protective tribofilm [68], which ensures a continuous self-replenishment mechanism for solid lubricant supply $[22,23]$.
Roughly, powder metallurgy technologies involve all or most of the following process steps: (i) mixing of powders to create a feedstock, (ii) forming (compaction of the feedstock), (iii) sintering, and (iv) secondary operations.

Several processing parameters must be strictly controlled such as the temperature and time of sintering, compression method, techniques for the dispersion of the solid lubricant particles in the volume of the composite, etc. Sintering is the most important step in the production of the composite. The variables in sintering are the atmosphere, heating rate, temperature, dwelling time, and cooling rate. The sintering temperature should be lower than the decomposition temperature of the solid lubricant. Reactions among the matrix, alloying elements, and solid lubricant, which result in loss of solid lubricant, should also be avoided. Several techniques of compaction, such as uniaxial die pressing, extruding, rolling, 3D prototyping, isostatic pressing, cold isostatic pressing, hot isostatic pressing, split die compaction, and powder injection moulding, have to be considered, depending on the geometry and properties desired for the composite material. For the production of self-lubricating composites, the most relevant techniques are uniaxial die pressing and powder injection moulding techniques (Fig. 1).

The dominant compaction technology in terms of both tonnage quantities and number of parts produced is die pressing. Secondary operations such as machining are virtually eliminated owing to the very close tolerances of the finished parts [69]. However, depending on the configuration (single or double action), this technique yields gradients of porosity that may eventually be very high [70-72]. Typically, the production cycle comprises the following: (i) mixing of the powders (base material, alloying elements, and lubricant) to form the feedstock; (ii) filling of a die cavity with the feedstock; (iii) compaction of the powder within the die with punches to form the compact; and (iv) sintering.

Our group recently introduced [14] the use of the double-pressing/double-sintering (DPDS) technique [73] originally developed by Hoeganaes Corporation [74] as a potential option for improving the mechanical strength of self-lubricating sintered composites. The 
goal of this method is to increase the density of composites by two-fold pressing.

Roughly speaking, in the metal injection moulding (MIM) process, metal powders and, eventually, precursors are pre-mixed with polymeric binders. The mixture is heated and forced under pressure into a die cavity (in a manner identical to the process used for injection moulded plastic parts) and then ejected after cooling. A subsequent debinding stage removes the polymer, and the final sintering ensures the component's required density (Fig. 1).

The debinding stage, during which the polymeric binder is removed, can greatly influence the mechanical properties of the sintered component. In our case, two steps are used for the debinding process. After the chemical debinding, subsequent plasma-assisted thermal debinding is applied. Thermal debinding, as well as sintering, is performed in a single thermal cycle (plasma-assisted debinding and sintering (PADS)) [75]. The plasma reactor, developed in Ref. [76], was specially designed for the PADS process and described in Refs. [75-77]. It allows the control of the processing temperatures and heating rates independently of the plasma parameters.

As already pointed out, the ideal microstructure of a self-lubricating composite should consist of solid lubricant particles regularly dispersed in a continuous matrix. Unfortunately, such an ideal distribution of the solid lubricant particles is not obtained simply by blending metallic and solid lubricant powders. To produce a self-lubricating sintered composite, there are basically two ways of dispersing the solid lubricant particles in the volume of the metal matrix [78, 79]:

i. mixing the solid lubricant particles with matrix powders;

ii. in situ generation of the solid lubricant particles during sintering by dissociation of a precursor.

In the first method, where the composite is obtained by mixing the metallic matrix powders with the solid lubricant particles, the shear stresses that occur during mixing and compacting spread the solid lubricant by shearing between the powder particles of the metal matrix. This leads to an undesirable arrangement in which the solid lubricant covers the metallic particles to a large extent [80]. The presence of these layers of insoluble solid lubricant hampers the formation of contacts between the particles during sintering. This results in a metallic matrix with a high degree of discontinuity (Fig. 2(a)) and leads to a composite material with reduced mechanical strength.

There are two possibilities to overcome these difficulties. The first one is to rearrange the solid lubricant phase in discrete agglomerates by the capillary action of a liquid phase. The second one is to produce the solid lubricant phase in situ during sintering by decomposition or dissociation of a precursor, giving rise to a more continuous and sound matrix (Fig. 2(b)).

Therefore, this work is a synthesis of previous works reporting the development of new, low-cost, self-lubricating composites combining a low friction coefficient with high mechanical strength and wear resistance, which are produced by both uniaxial die

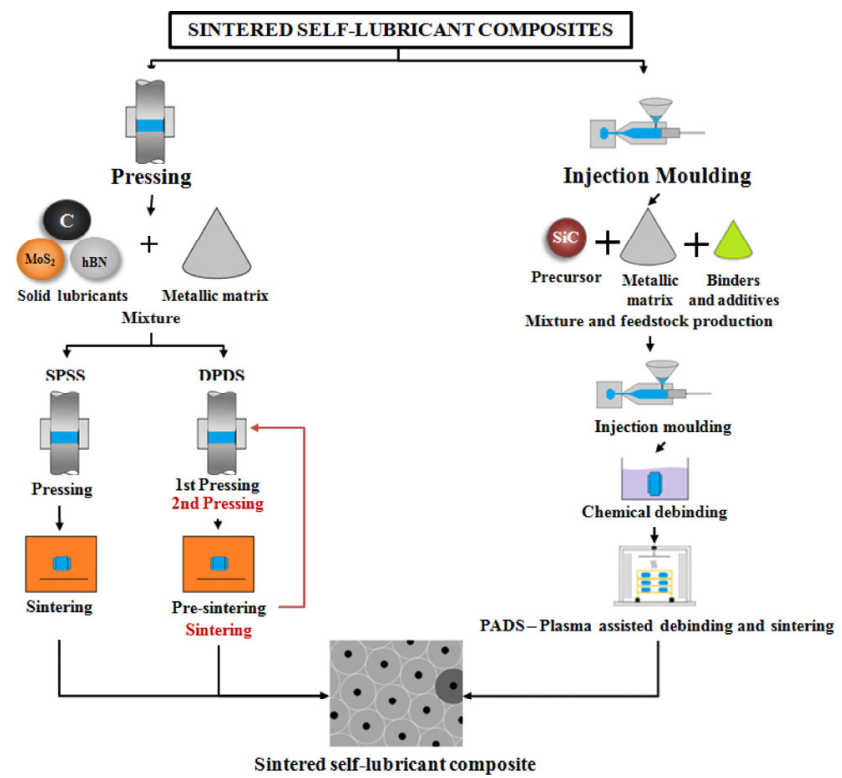

Fig. 1 Main powder metallurgy processing routes for obtaining self-lubricating composites.

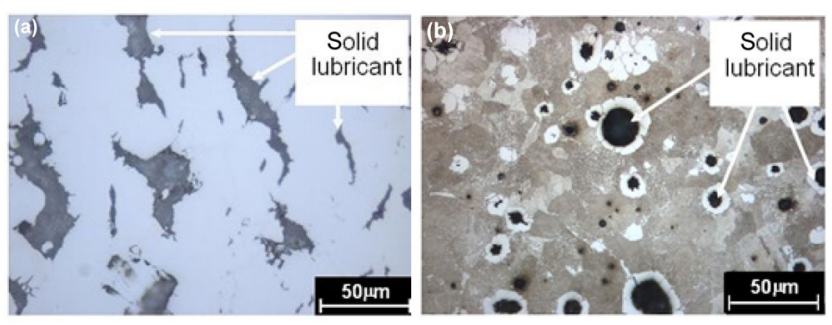

Fig. 2 Solid lubricant particle dispersion. (a) Mixing of powders prior to compaction. (b) In situ generation by decomposition of a precursor [81]. 
pressing of solid lubricant particles mixed with matrix powders and metal injection moulding associated with the in situ generation of solid lubricant particles.

\section{Materials and methods}

\subsection{Metal injection moulding}

As well described in previous works [2, 15, 48, 82], carbonyl iron powder was mixed with the elemental powder of the alloying elements to produce iron-based composites. Varying amounts of $\mathrm{SiC}$ powder $(1,2,3$, 4 , and $5 \mathrm{wt} \% \mathrm{SiC}$ ) were also added. The feedstock for injection was prepared in a Haake Sigma mixer $\left(180^{\circ} \mathrm{C}\right.$, $70 \mathrm{rpm}, 90 \mathrm{~min}$ ) using $8 \mathrm{wt} \%$ of an organic binder system containing paraffin wax, polypropylene, stearic acid (surfactant), ethylene vinyl acetate copolymer (EVA), and amide wax. The specimens were injected (injection pressure $=100 \mathrm{MPa}$, temperature $=180{ }^{\circ} \mathrm{C}$ ) using an Arbourg $320 \mathrm{~S}$ injection moulding machine. The debinding was performed in two steps: a chemical debinding followed by plasma-assisted thermal debinding. A single thermal cycle was employed for both the thermal debinding and the sintering, using a so-called PADS process [75-77]. The isothermal sintering was processed at $1,100{ }^{\circ} \mathrm{C}, 1,150{ }^{\circ} \mathrm{C}$, and $1,200{ }^{\circ} \mathrm{C}$ for $60 \mathrm{~min}$.

To evaluate the influence of the matrix on the tribological behaviour, we also produced three different compositions of a 3\% SiC composite (Fe-Si-C, Fe-Si-C-Ni, and Fe-Si-C-Ni-Mo). Polishing of the specimens was performed manually with a 1200-, 2400-, and 4000-grit sandpaper for $10 \mathrm{~min}$ and $150 \mathrm{rpm}$ in a polishing machine with automatic control of the time and rotation.

\subsection{Die pressing}

To evaluate the synergy between the different particles of the solid lubricant, we used the conventional route of powder metallurgy. Mixtures were produced using iron as the main constituent of the matrix composite, silicon as an alloying element for stabilization of the iron alpha phase and as a hardener of the matrix, and graphite and hexagonal boron nitride as solid lubricants. The total content of the solid lubricant $(5,7.5$, and $10 \mathrm{vol} \%)$ as well as the h-BN amount
(1, 1.75 and $2.5 \mathrm{vol} \%)$ and graphite content was varied. The powders were homogenized in a Y-type mixer before being uniaxially pressed at $600 \mathrm{MPa}$ inside a floating die using a double-action press. After the compaction, the specimens were sintered in a hybrid plasma reactor.

To study the effect of double pressing/double sintering, we added $2.5 \mathrm{wt} \%$ graphite $+5.0 \mathrm{wt} \%$ hexagonal boron nitride (h-BN) to a ferrous matrix based on a Fe-1.5Mo-1.0Si-0.8C alloy and then compacted and sintered them. As to the compaction step, three alternatives were applied: The first two routes used single-pressing/single-sintering standard die pressing, whereas the third used double pressing/ double sintering [14]. The specimens produced by single pressing/single sintering were compacted at 500 and $700 \mathrm{MPa}$, respectively, and then sintered in a hybrid plasma reactor. The specimens produced by double pressing/double sintering were initially pressed at $500 \mathrm{MPa}$ and then pre-sintered at $700{ }^{\circ} \mathrm{C}$ for $30 \mathrm{~min}$. After they were cooled to room temperature, a higher pressure $(700 \mathrm{MPa})$ was used in a secondary pressing step. Finally, the specimens were sintered at high temperature under conditions identical to those used for the single-pressed specimens.

Again, the processing routes are well described in previous works [14, 83].

To study the effect of solid lubrication combined with a liquid lubricant in a cooperative lubrication regime, we produced sintered composites that contain particles of the solid lubricant dispersed in a metallic matrix. The processing route is detailed in a recent publication [9], and Table 1 presents the material nominal composition.

\subsection{Tribological evaluation}

In all cases, the mechanical properties were evaluated

Table 1 Chemical composition of the materials used.

\begin{tabular}{ccccccccc}
\hline \multirow{2}{*}{ Alloy } & & \multicolumn{3}{c}{ Elements } & \multicolumn{3}{c}{ Lubricants } \\
\cline { 3 - 8 } & Name & Fe & $\begin{array}{c}\mathrm{C} \\
(\%)\end{array}$ & $\begin{array}{c}\mathrm{Si} \\
(\%)\end{array}$ & $\begin{array}{c}\text { Mo } \\
(\%)\end{array}$ & $\begin{array}{c}\text { Graphite } \\
(\%)\end{array}$ & $\begin{array}{c}\text { hBN } \\
(\%)\end{array}$ \\
\hline \multirow{2}{*}{ Self-lubricating } & $\mathrm{C}$ & Bal. & 0.6 & 1 & - & 2.5 & 5 \\
& $\mathrm{P}$ & Bal. & 0.8 & 1 & 1.4 & 2.5 & 5 \\
\multirow{4}{*}{ Matrix } & $\mathrm{CM}$ & Bal. & 0.6 & 1 & - & - & - \\
& $\mathrm{PM}$ & Bal. & 0.8 & 1 & 1.4 & - & - \\
\hline
\end{tabular}


by micro-hardness and tensile tests (MPIF standard 10) [84], whereas the tribological behaviour was evaluated using two experimental routes (Fig. 3):

a. Reciprocating sliding tests were carried out at a constant normal load to obtain the friction coefficients and wear rates of the specimens and counter-bodies.

b. Incremental loading was used in reciprocating the sliding tests at regular increments of $7 \mathrm{~N}$ every $10 \mathrm{~min}$ to assess the scuffing resistance, defined as the work $(\mathrm{N} \cdot \mathrm{m})$ until the friction coefficient first achieved values higher than 0.20 , meaning the loss of the lubricity effect [85].

All tests were conducted under a constant stroke (5 mm), frequency $(2 \mathrm{~Hz})$, relative humidity $(50 \%)$ and temperature $\left(22 \pm 4{ }^{\circ} \mathrm{C}\right)$. In all the experimental routes, a hard steel AISI 52100 ball (diameter 5 or $10 \mathrm{~mm}$ ) fixed to a pivoted arm rested against the specimen surface.

For the lubricated tests, 3D triboscopic maps [86] allowed a better visualization of the evolution of the friction coefficient (axis $z$ ) with the position of the counter-body within each cycle (axis $x$, measured by an additional linear variable differential transformer sensor) and with the total number of cycles (axis $y$ ). This required the adaptation of a high-frequency acquisition system to the tribometer. A specially developed LabView ${ }^{\circledR}$ interface was used to produce the 3D maps. The use of triboscopy can help to identify localized events as well as a global evolution, and the technique is well described in Ref. [87].

The tests, detailed in a recent paper [9], were conducted under controlled relative humidity (50\%) and temperature $\left(22 \pm 4{ }^{\circ} \mathrm{C}\right)$ under dry and lubricated (ISO 5 alkylbenzene linear oil $+2 \% \pm 0.5 \%$ BTP) configurations.

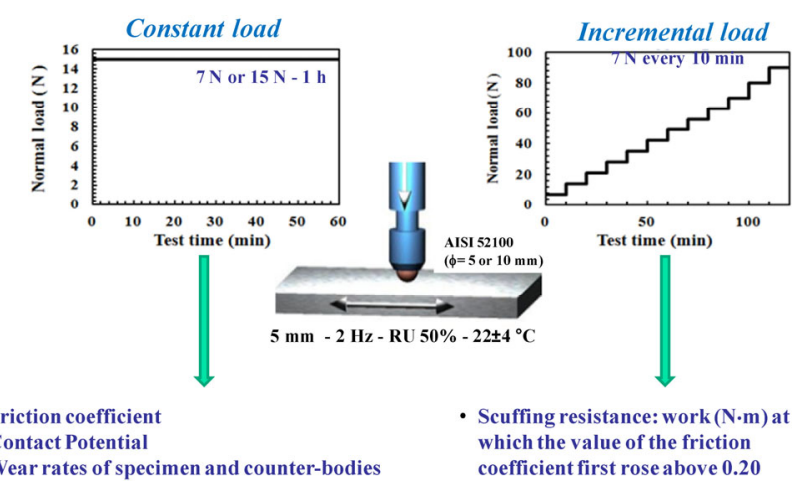

Fig. 3 Tribological characterization.
Wear scars and microstructures were studied using scanning electron microscopy with energy dispersive X-ray (SEM-EDX), transmission electron microscopy (TEM), X-ray diffraction, field emission gun scanning electron microscopy, micro Raman spectroscopy, Auger electron spectroscopy, and white light and laser interferometry. The near-surface porosity was evaluated from transversal sections at $150 \mu \mathrm{m}$ below the surface using 50 images for each specimen and the software Analysis ${ }^{\circledR}$.

\section{Results and discussion}

\subsection{Metal injection moulding}

The reference alloy presented a microstructure constituted of pearlite $(\mathrm{P})$ and ferrite whereas the addition of $\mathrm{SiC}$ to the feedstock powder induced the formation of graphite nodules. Ferrite rings indicated by $\alpha$ surround the graphite nodules, indicated by $G$ (Fig. 4(a)).

Thermodynamics can, in fact, predict the formation of this microstructure [68]. The parameters influencing the microstructural evolution are the amount of $\mathrm{SiC}$
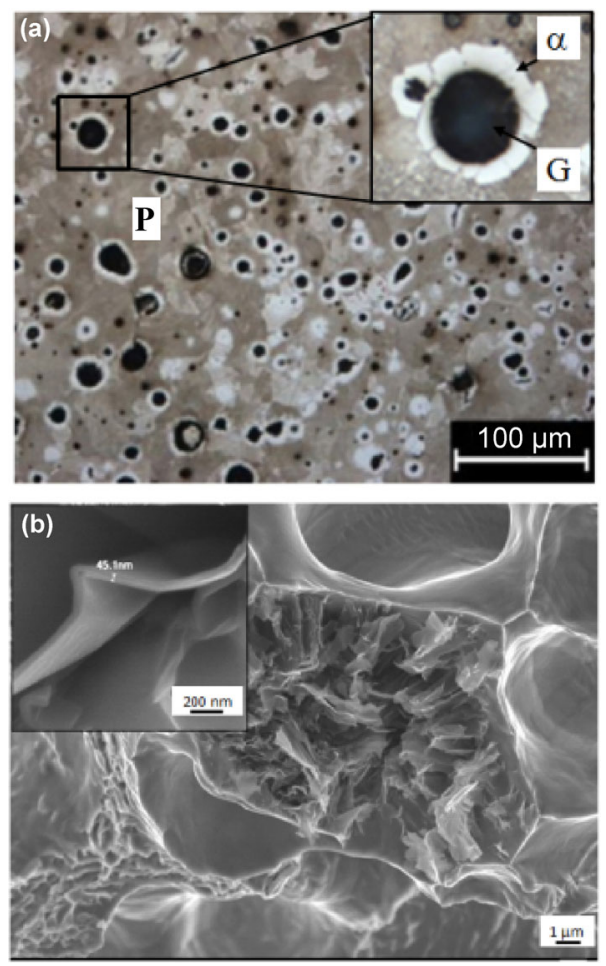

Fig. 4 Typical aspects of the microstructure. Alloy $\mathrm{Fe}+0.6 \mathrm{C}+$ 4Ni. (a) General aspect, 2\% SiC; (b) graphite nodule, 3\% SiC. 
and the sintering temperature and time [81]. This is well described in a recent paper [68]. Roughly, at the initial stage of the dissociation of the $\mathrm{SiC}$ particles, silicon and carbon atoms diffuse into the ferrous matrix. However, the continuous Si enrichment of the ferrous matrix leads to the stabilization of the body-centred cubic structure of the ferrous matrix (ferrite) and yields very low carbon solubility and, thus, drastically reduces the dissolution of carbon. The dissolution of silicon, in contrast, is maintained. As a consequence, ferrite rings are formed around the former $\mathrm{SiC}$ particles. The remaining carbon forms graphite nodules (size $\leq 20 \mu \mathrm{m}$ ). The detail shown in Fig. 4(b) evidences, from a cryogenically fractured surface, that the nodules are nanostructured, composed of stacking of graphite layers with a few tenths of nanometres thick.

The influence of the precursor content and of the sintering temperature on the steady-state friction coefficient under a constant normal load is synthesized in Fig. 5.

The average friction coefficient decreased as the precursor content (and, as a consequence, the number of graphite nodules) increased, independently of the sintering temperature. In general, the reduction was substantial (up to $3 \% \mathrm{SiC}$ ). For values greater than $3 \% \mathrm{SiC}$, the friction coefficient was almost constant.

Moreover, the sintering temperature hardly affected the friction coefficients. All composites showed considerably lower friction coefficients than the matrix alloys (graphite-free alloys).

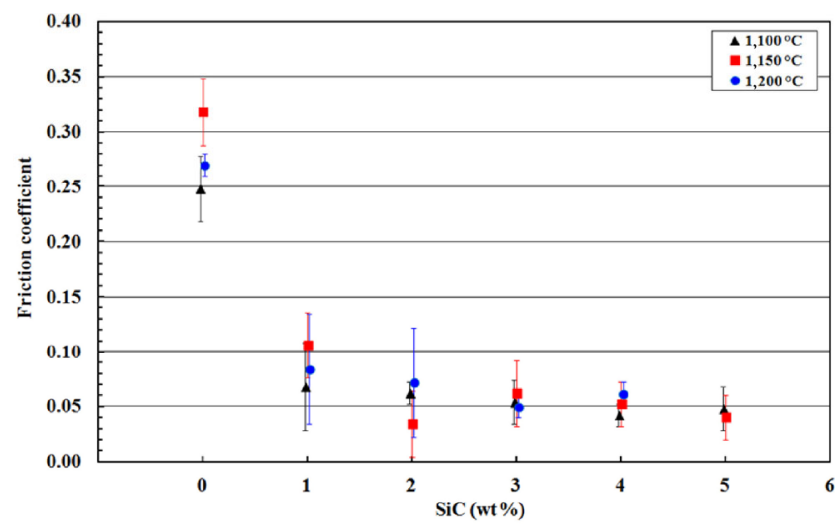

Fig. 5 Effect of silicon carbide content and sintering temperature on the steady-state friction coefficient. Constant load mode, Hertz stress $0.88 \mathrm{GPa}$. The $x$ values were slightly shifted $( \pm 0.02)$ to the left and right for better visualization [48].
In previous papers $[2,15]$, we concluded that there was, unquestionably, no correlation between the friction coefficient and the mechanical properties of the composites. The outstanding tribological behaviour of these newly developed sintered composites was traced back to the occurrence of a so-called turbostratic 2D graphite, which, according to the literature, has highly misoriented graphene planes. Additionally, the interlamellae distances in 2D turbostratic graphite are much longer than those in highly oriented 3D graphite.

We supposed that graphite foils were removed from the in situ generated graphite nodules and remained at the interface [2]. If the reservoirs remain active (open), there will be a continuous self-replenishment of solid lubricants to the contact area and, as a consequence, the maintenance of a protective tribolayer. The small size of the powders in MIM processes makes the mean free path among graphite nodules also small. This ensures an easy "coverage" with the solid lubricant of the surface between the nodules.

To make this point clear, we tested other types of graphite under the same imposed tribological parameter; they were graphite nodules in a nodular cast iron, and the contact was flooded in graphite powder. The graphite-free alloy $(0.6 \mathrm{wt} \% \mathrm{C}$ steel) was also tested as a reference. Figure 6 shows the average friction coefficients (steady state) of the different materials.

The sintered steel had the highest friction coefficient. The presence of graphite (nodules in a nodular cast iron and graphite in powder) induced a strong reduction in the friction coefficient. Further reduction in the friction coefficient was observed when $3 \% \mathrm{SiC}$ was

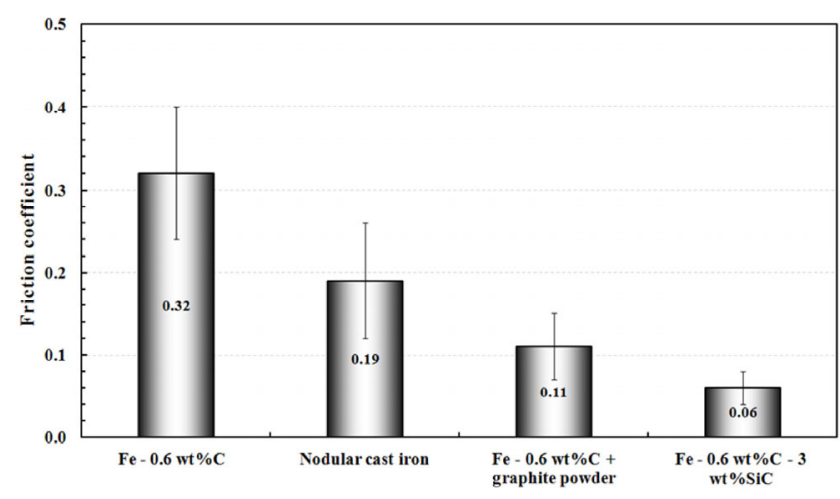

Fig. 6 Variation in the steady-state friction coefficient with the type of graphite. Constant load mode, Hertz stress 0.88 GPa [48]. 
added, where remarkably low friction coefficient values (0.06) were achieved.

Typical Raman spectra of the different graphite types clearly showed a $G$ band at approximately $1,580 \mathrm{~cm}^{-1}$. Graphite associated with graphite powders and nodular cast iron is characterised as a 3D graphite and is highly aligned according to the literature [48]. The spectrum of the graphite nodules produced by the $\mathrm{SiC}$ decomposition clearly showed a D and a $\mathrm{D}^{\prime}$ band (associated with crystallinity disorder). The analysis of the spectra $[15,48,68]$ showed strong evidence of the presence of turbostratic 2D graphite, including widening of the bands, the ID/IG ratio, the size of the graphite crystallites and the shape of the second-order $G^{\prime}$ band. The large interplanar distances ( $\geq 3.499 \AA$ A vs. $3.354 \AA$ f for the highly aligned 3D graphite) between the graphene foils and the misorientation of these foils were confirmed by TEM, as illustrated in Fig. 7.

The interaction between the graphene planes was strongly reduced by the large spaces between them, resulting in low shear strength. Thus, it is reasonable to suppose that, during reciprocating sliding, the graphite planes easily sheared, maintaining the contact interface highly lubricated.

On the other hand, scuffing resistance was clearly affected by the sintering temperature (Fig. 8). Signifi-
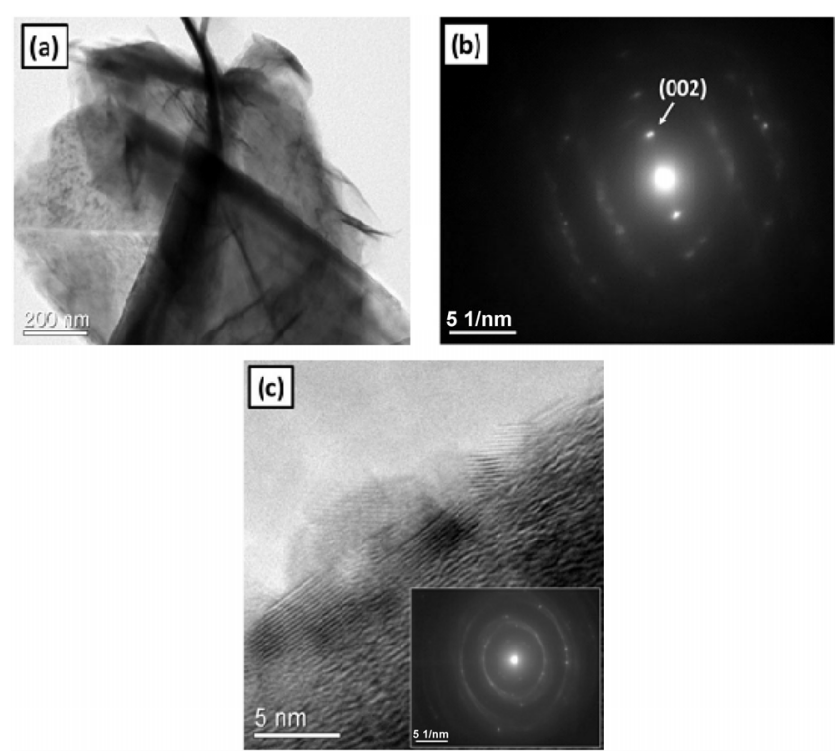

Fig. 7 Typical TEM results. (a) Bright fields of the turbostratic graphite layers. (b) SAED showing the interlamellae space. (c) HRTEM image of graphite sheets obtained from graphite nodules in the $\mathrm{Fe}+0.6 \mathrm{C}+3 \mathrm{SiC}$ specimen [68]. cantly higher scuffing resistance $(5 \times)$ was produced by low sintering temperatures. To advance this point, we used SEM to analyze cryogenically fractured samples sintered at $1,100{ }^{\circ} \mathrm{C}$ [2]. The analysis showed the presence of partially dissociated $\mathrm{SiC}$ particles within the graphite nodules (insert in Fig. 8). They probably induced a greater load-bearing capacity and the protection of the matrix/tribolayer, increasing the scuffing resistance [2].

The addition of alloying elements to the composites produced different matrices. As already reported, the addition of $\mathrm{SiC}$ to the feedstock powder created graphite nodules in all three microstructures, whereas the metallic matrix varied from ferrite to martensite. Si-stabilized ferrite, with a very small fraction of pearlite, was predominant for the reference alloy $(\mathrm{Fe}+0.6 \% \mathrm{C})$. The addition of nickel did not substantially change the microstructural constituents, whereas for the $\mathrm{Ni}+$ Mo containing alloy the metallurgical constituents changed from ferrite/pearlite to martensite [15].

The influence of metallic matrix on the steady-state friction coefficient is synthesized in Fig. 9. The reference alloy, Fe-C, had the highest mean friction coefficient (0.11). The addition of alloying elements considerably reduced the friction coefficient values ( $45 \%$ reduction for the Ni alloys) to as low as 0.04 (65\% reduction) for the Fe-C-Ni-Mo steels [15].

The wear rates of the specimens and counter-bodies are summarized in Fig. 10. Besides presenting a different general appearance, the wear scars presented different widths. Inside the wear scars, there was clear evidence of abrasive wear, shown by the presence

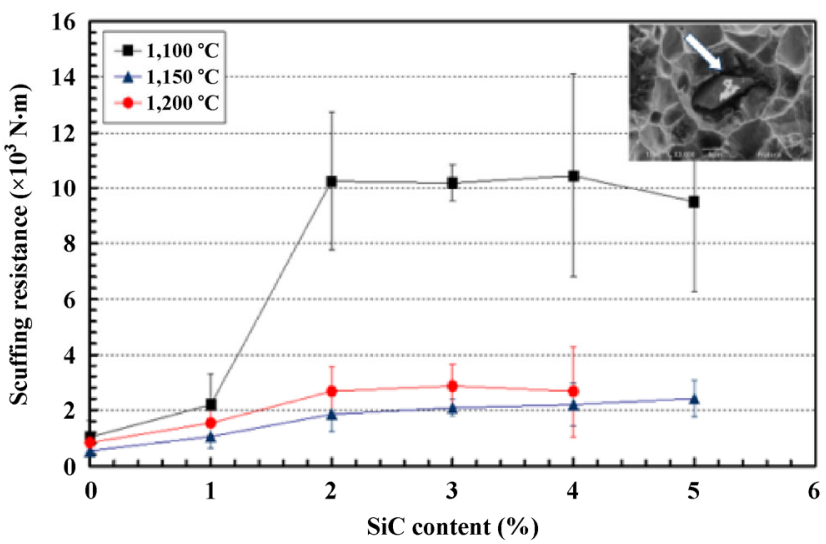

Fig. 8 Effect of $\mathrm{SiC}$ content and sintering temperature on the scuffing resistance. Incremental loading mode (increments of $7 \mathrm{~N}$ every $10 \mathrm{~min}$ ) [2]. 


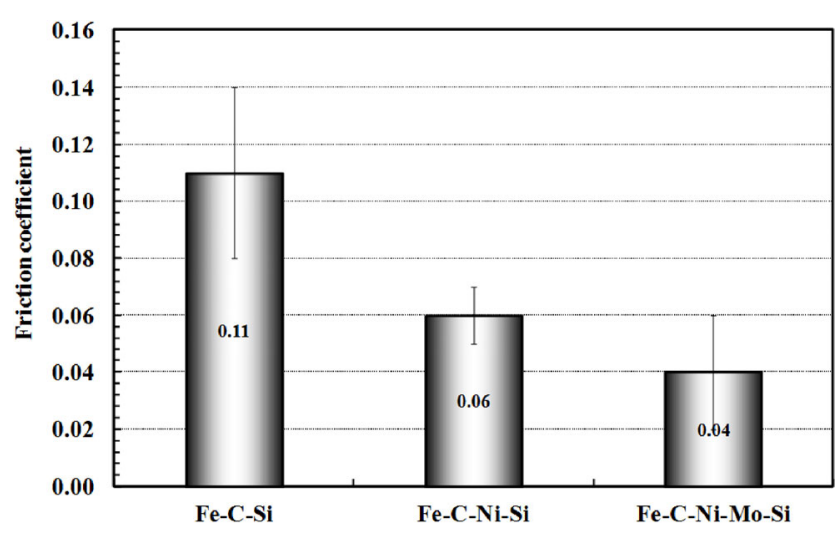

Fig. 9 Effect of metallic matrix on the friction coefficient. Constant load mode, Hertz stress 0.88 GPa [15].

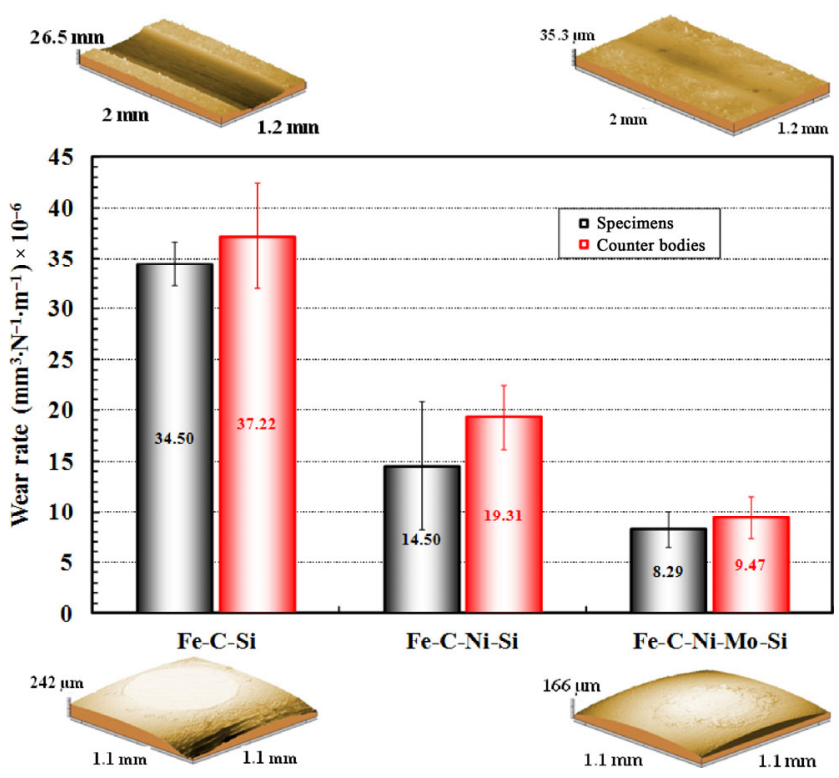

Fig. 10 Wear rates of the self-lubricating composites and AISI 52100 steel ball. Constant load mode, Hertz stress 0.88 GPa [15].

of multiple parallel scratches [15]. The intensity and number of scratches varied according to the material. The wear loss of the counter-bodies exhibited the same behaviour.

Composites containing alloying elements had the lowest wear rates. The reductions in the friction coefficient and the wear of the tribological pair could be associated with the tribofilm transfer effects from the self-lubricating composite to the counter-body and vice-versa. The existence of the protective tribolayer continually avoided metal-to-metal contact and was associated with the resistance of the metallic matrix to plastic deformation and, consequently, to the sealing of lubricant reservoirs [15].

Figures 11(a) and 11(b) presents the dominant Raman
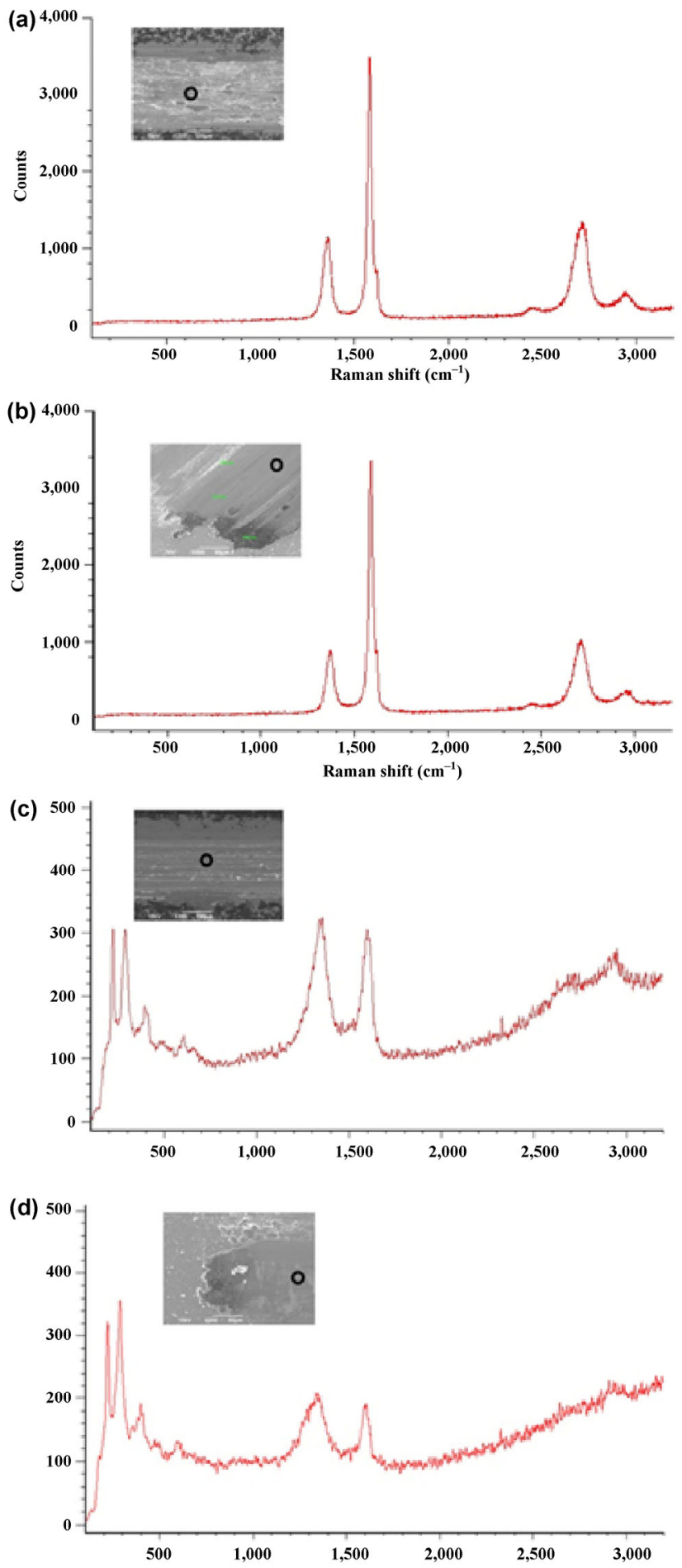

Fig. 11 Typical Raman spectra. (a) Fe-C-Ni-Mo specimen. (b) Fe-C-Ni-Mo counter-body. (c) Fe-C specimen, centre of the scar. (d) Fe-C counter-body, centre of the scar [15].

spectra found in the wear scar for the Fe-C-Ni-Mo alloy.

The spectra of the tribolayers present in the wear scars of the specimens or in the counter-bodies were 
almost identical and clearly showed the beneficial presence of turbostratic 2D graphite on both sides of the tribo-pair.

On the other hand, the position in the wear scar affected the spectra found in the wear scar of the reference alloy. Close to the edges of the wear marks, spectra similar to those found in the previous case were measured, whereas those found in the centre of the scar were, to some extent, different (Figs. 11(c) and 11(d)). Aside from exhibiting lower intensities of the 2D graphite characteristic bands and a certain amount of fluorescence, the spectra also showed other smaller bands at lower frequencies. The origin of these bands was attributed to the formation of iron oxide by tribochemical reaction caused by the surrounding atmosphere. High friction coefficients provide a large amount of energy to induce tribochemical reactions. Very likely, iron oxides should induce inferior tribological performance [15].

Figure 12 shows how the surface finish affects the evolution of the friction coefficient during the test duration.

There was a pronounced transient associated with the onset of contact between the specimen and the counter-body at the beginning of the tests before a steady state was reached. The reasons for the difference in the evolution of the friction coefficient within the transient period are not yet well understood and will not be treated in the present paper. The values of the friction coefficient for each test were computed by averaging the steady-state values. The results are summarized in Fig. 13.

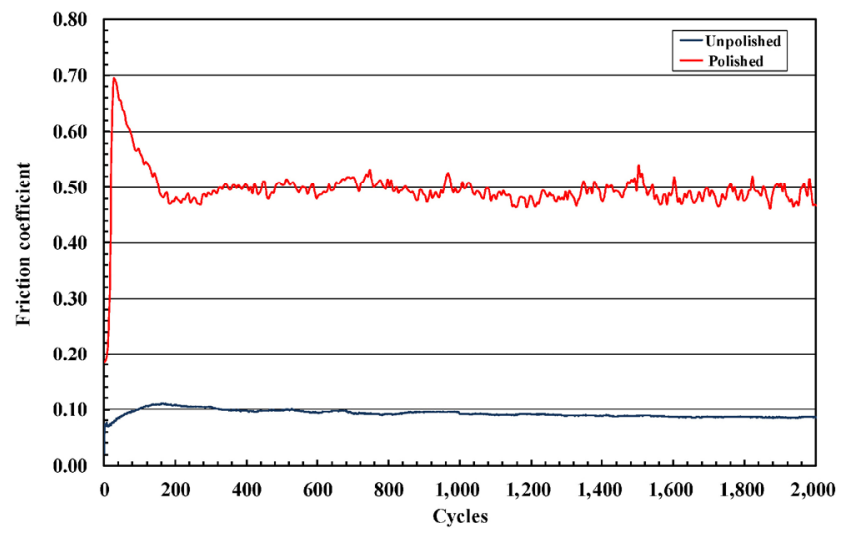

Fig. 12 Typical evolution of the friction coefficient with the number of cycles. $3 \% \mathrm{SiC}$, constant load mode, Hertz stress 0.88 $\mathrm{GPa}[82]$.

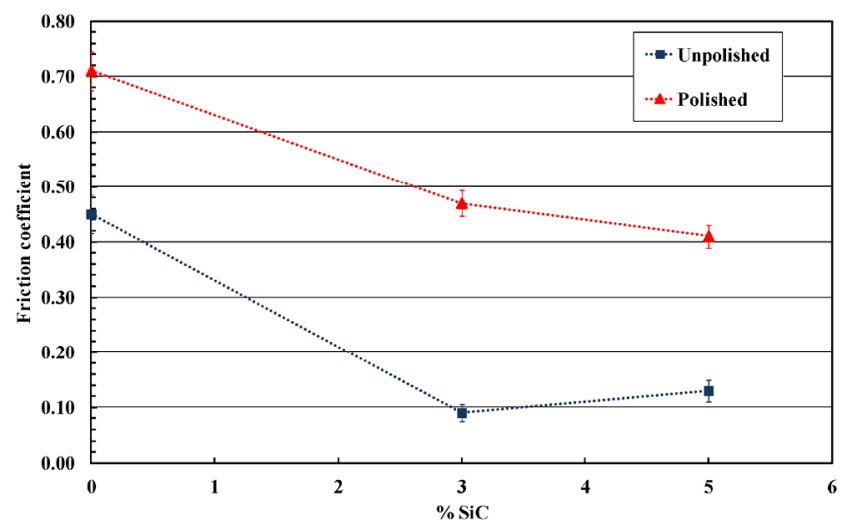

Fig. 13 Steady-state friction coefficient. Constant load mode, Hertz stress $0.88 \mathrm{GPa}$ [82].

The friction coefficient was strongly influenced by the surface finish. Polished specimens exhibited significantly higher friction coefficients $(\mu \geq 0.4)$, suggesting that the $2 \mathrm{D}$ turbostratic graphite nodules did not actively participate in the tribolayer formation. In fact, multi-elemental X-ray maps obtained by energy dispersive X-ray spectroscopy (EDS) clearly showed a large decrease in the amount of graphite nodules for the polished surface [82]. It can be concluded that, besides significantly reducing the surface roughness, polishing also affected the availability of solid lubricant reservoirs in the active sliding interface.

In addition, the friction coefficient decreased when the amount of precursor (SiC) increased for both surface finishing routes. The reference specimen $(0 \% \mathrm{SiC})$ had a mean friction coefficient significantly higher than those of the samples containing 3\% and $5 \% \mathrm{SiC}$.

\subsection{Die pressing}

Although compaction pressure had almost no influence on the microstructure of the specimens produced with the purpose of investigating the double-pressing/ double-sintering (DPDS) processing route (all specimens exhibited a homogeneous dispersion of two different types of solid lubricant: graphite and hBN reservoirs), it strongly influenced their mechanical properties. A small increase $(20 \%)$ in the ultimate tensile strength occurred owing to an increase in compaction pressure from 500 to $700 \mathrm{MPa}$, whereas double pressing/double sintering significantly improved the mechanical strength $(50 \%-80 \%)$ [14]. 
Conversely, the effect of the production route on the friction coefficient and wear rate of both the specimens and the counter-bodies was marginal under a constant load tribological test configuration. For the singlepressing/single-sintering tests, there was a high level of dispersion of the results, which was significantly reduced when double-pressed/double-sintered specimens were tested. Finally, the wear rates of the counter-bodies were greater $(4 \times)$ than those of the specimens, suggesting tribochemical effects [14].

Open reservoirs of the solid lubricant inside the wear tracks after the sliding test were a common characteristic of all the specimens investigated. Hypothetically, this effect ensured a continuous re-supply of solid lubricants to the contact, thus constantly maintaining the system in the lubricious regime $(\mu<0.2)$. The establishment of a protective tribolayer, which contained many randomly distributed cracks, probably originated by its spalling and destruction, was another important feature in almost all of the studied wear tracks. EDS micro-analysis of the tribolayers undoubtedly revealed a strong presence of oxygen and carbon when compared with the unworn surface [14].

Peaks at approximately 1,360 and $1,590 \mathrm{~cm}^{-1}$ were identified in the Raman spectra of the tribolayers, as commonly found in carbonaceous materials [14]. The peak at 1,590 $\mathrm{cm}^{-1}$ was found for a carbon-based material that contained an $\mathrm{sp}^{2}$-hybridised carbon. The peak at approximately $1,360 \mathrm{~cm}^{-1}$, the $\mathrm{D}$ band, was related to a disordered carbon [88, 89]. The hexagonal boron nitride also had a Raman band close to $1,360 \mathrm{~cm}^{-1}$ $[90,91]$. Owing to the overlapping of the $\mathrm{h}-\mathrm{BN}$ and $\mathrm{D}$ bands, Raman analysis of the tribolayer was rather complex. Indeed, it was difficult to establish whether the peak close to $1,360 \mathrm{~cm}^{-1}$ was due solely to h-BN or due to a contribution of a disordered graphite that originated during sliding. Moreover, low-intensity bands at lower frequencies $\left(100-500 \mathrm{~cm}^{-1}\right)$ were also found in the Raman spectra, possibly related to the presence of iron oxides [92]. The evolution of the contact resistance throughout the tests was another evidence of physico-chemical modifications during sliding [14].

The behaviour of all specimens in the lubricious regime $(\mu<0.2)$ was similar, as demonstrated in
Fig. 14(a). This figure depicts the typical evolutions of the friction coefficient and applied normal load with sliding distance in incremental load tests. The single-pressed/single-sintered specimens (SP-500 and SP-700) exhibited a lower and nearly equivalent scuffing resistance. On the other hand, the lubricious regime was longer for the DPDS specimen. The scuffing resistance of the composites was strongly influenced by the compaction step (Fig. 14(b)). Increasing the compaction pressure for the SPSS specimens increased substantially the scuffing resistance $(43 \%)$, whereas DPDS resulted in greater improvement in the durability of the tribolayer (60\% to $130 \%$ ).

Additional interrupted scuffing tests helped to further elucidate the creation and deterioration of the tribolayer (Fig. 14(a)). Stop A was associated with the establishment of the tribolayer, whereas stop B was connected with the final stages, e.g., after the breakdown of the lubricious regime $(\mu>0.20)$.

The wear tracks associated with stops A and B are illustrated in Figs. 15(a) and 15(b), respectively.

At the beginning of the process (stop A), the tribolayer, indicated by arrows, had a smooth aspect
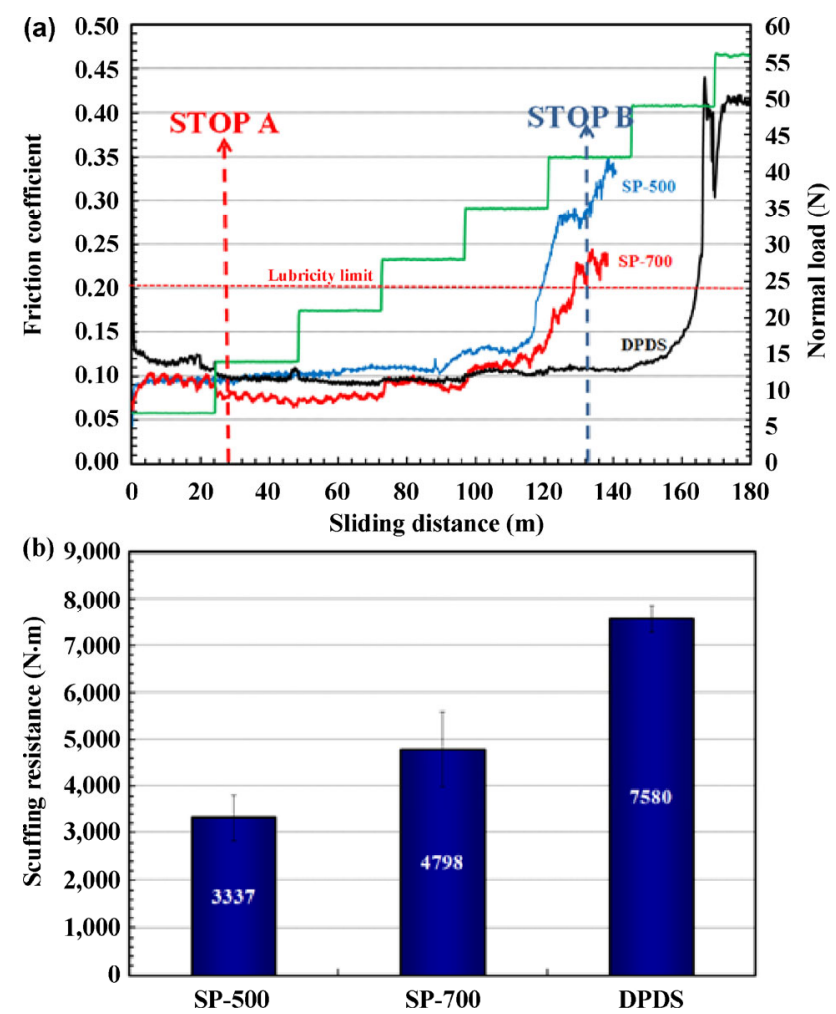

Fig. 14 Incremental normal load tests. (a) Friction coefficient and applied load's typical evolution. (b) Scuffing resistance [14]. 

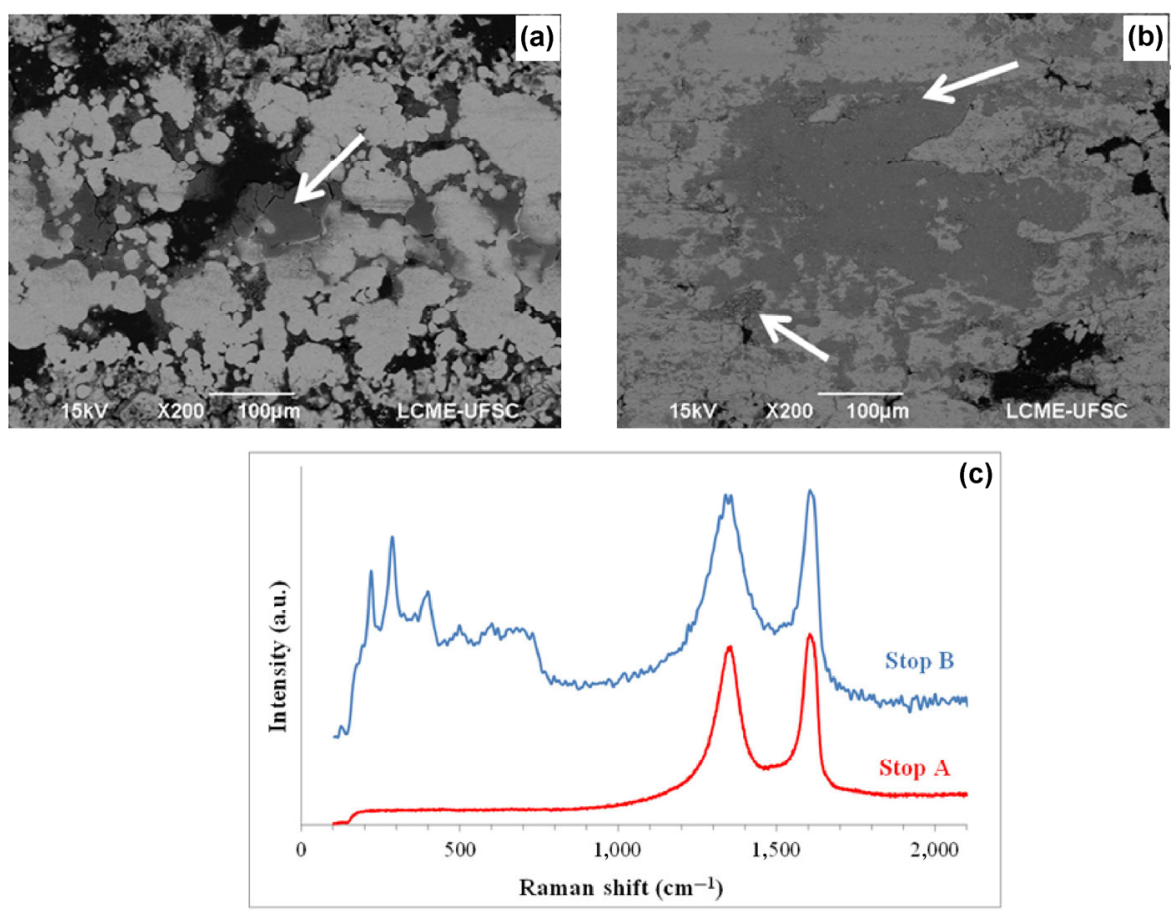

Fig. 15 Evolution of the tribolayers with the testing time. (a) BSE image, stop A. (b) BSE image, stop B. (c) Raman spectra [14].

and clearly originated in sites close to the lubricant reservoirs and then spread over the metallic matrix surface. After its collapse (stop B), the tribolayer was fragmented, with the generation of a large amount of debris (arrows). Furthermore, Raman spectroscopy (Fig. 15(c)) showed that the tribolayer was dissimilar in the two conditions. Under the conditions coupled with stop A, the spectrum only showed peaks relative to graphite, whereas the spectra for the conditions associated with stop B had, in addition, smaller bands at lower frequencies. The origin of these peaks can be attributed to the development of iron oxide by a tribochemical reaction with the surrounding atmosphere [14]. There was reasonable accordance of the peaks in the range between 225 and $650 \mathrm{~cm}^{-1}$ with those conventionally reported for iron oxide. The peaks at 290, 408,497 and $607 \mathrm{~cm}^{-1}$ indicated the presence of hematite $\alpha-\mathrm{Fe}_{2} \mathrm{O}_{3}$, whereas the peak at $667 \mathrm{~cm}^{-1}$ was assigned to magnetite $\mathrm{Fe}_{3} \mathrm{O}_{4}$ [93-95].

The near surface of the transversal sections of the specimens exhibited an evidently strong difference in porosity (inserts in Fig. 16). DPDS specimens showed porosity values around $25 \%-32 \%$ lower when compared to SPSS specimens. German [96] reported that mechanical strength can increase by up to $20 \%$ when porosity reduces to $2 \%-3 \%$. In fact, ultimate tensile strength has shown a linear relationship with porosity [14].

The variation in scuffing resistance with porosity showed a similar relationship (Fig. 16). It seems that scuffing resistance depended on the mechanical support provided by the matrix. Increasing the compaction pressure induced a diminution in porosity, which increased the mechanical properties. Ultimately, better mechanical support was achieved, increasing markedly the durability of the protective tribolayer and, therefore,

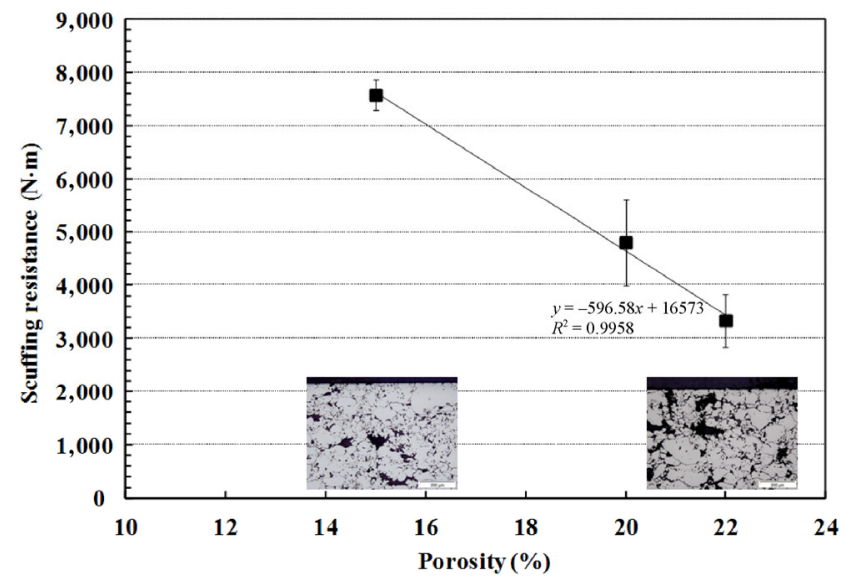

Fig. 16 Correlation between porosity and scuffing resistance. 
the scuffing resistance.

The simultaneous addition of $\mathrm{hBN}$ and graphite induced an increase in the solid lubricant reservoirs homogeneously dispersed in the metallic matrix [83]. As expected, an increase in the solid lubricant reservoirs was observed when the total solid lubricant content increased, regardless of their solubility in the ferrous matrix. A reduction in the tensile strength was observed with an increase in the total solid lubricant content. In addition, a decrease in the ultimate tensile strength (UTS) within the three levels of the total solid lubricant was observed for increased volume percentages of hBN [83]. Solid lubricant reservoirs may be considered discontinuities in the metallic matrix and have a negative influence on the mechanical properties of sintered composites [2, 47, 61]. However, the use of graphite generates microstructural changes in which diffusion into the matrix may overcome the deleterious effect on the mechanical properties, but reduces the final amount of solid lubricant and compromises the tribological properties. Such metallurgical aspects, as the combined effect of graphite and hBN in the microstructural and tribological evolution of composites, are currently under investigation by our group. The presence of solid lubricant particles induced a complex evolution of the composite mechanical properties:

a. Strengthening of the metallic matrix due to the solubility of solid lubricants into the metallic matrix, in particular carbon diffusion from graphite, increasing the mechanical resistance.

b. Decreased mechanical resistance because of the solid lubricant particles, reducing the degree of continuity of the metallic matrix.

In the present case, it can be claimed that the reduction in continuity of the metallic matrix plays a dominant role. Typical etched composite microstructures, produced with 5 and $10 \mathrm{vol} \%$ of the total solid lubricant, can be observed in Fig. 17, in which the specimen containing the highest amount of solid lubricant (Fig. 17(b)) also possesses the higher amount of graphite.

All composites had an almost pearlitic matrix microstructure, with the presence of ferrite grains in the original location of pre-alloyed iron-silicon (Fe + $45 \mathrm{wt} \% \mathrm{Si}$ ) particles and proeutectoid cementite phases along the grain boundaries. The latter increased with the initial graphite content (Fig. 17(b)). When composites are sintered above the ferrite-austenite transformation temperature, enhanced diffusion of carbon into the matrix is likely to occur, further improving the matrix mechanical properties by solid solution and precipitation hardening mechanisms $[97,98]$. Figure 18 shows the typical friction coefficient evolution with the test time of the samples produced with $5,7.5$, and $10 \mathrm{vol} \%$ of the total solid lubricant content. The friction coefficient of the initial lower
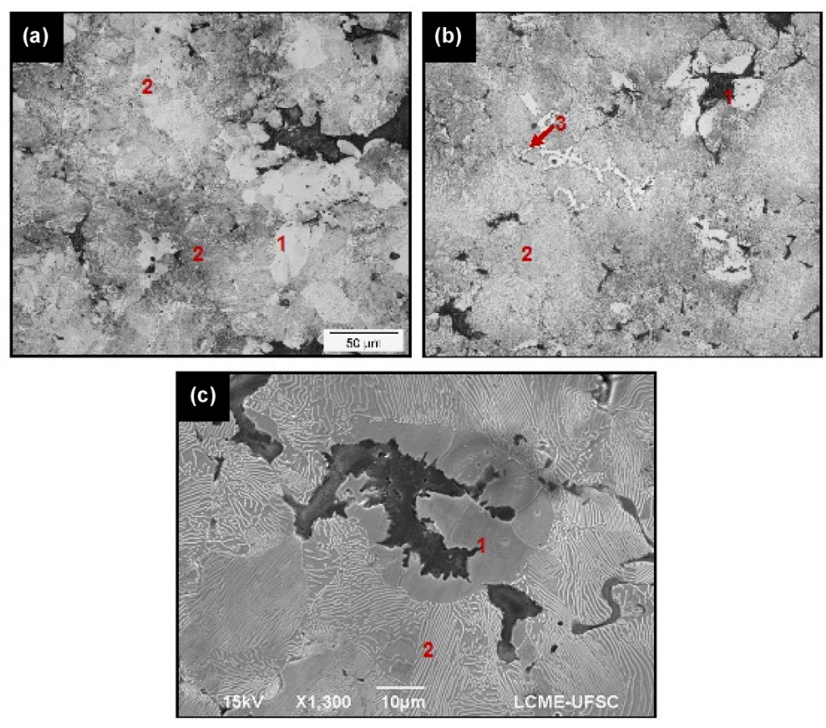

Fig. 17 Typical microstructures of the samples, containing 5 and $10 \mathrm{vol} \%$ of solid lubricant, presenting ferrite (1), perlite (2), and cementite (3). (a) $1 \mathrm{vol} \% \mathrm{hBN}+4 \mathrm{vol} \% \mathrm{C}$, (b) $1 \mathrm{vol} \% \mathrm{hBN}+$ $9 \mathrm{vol} \% \mathrm{C}$, and (c) $2.5 \mathrm{vol} \% \mathrm{hBN}+7.5 \mathrm{vol} \% \mathrm{C}$ (SEM) [83].

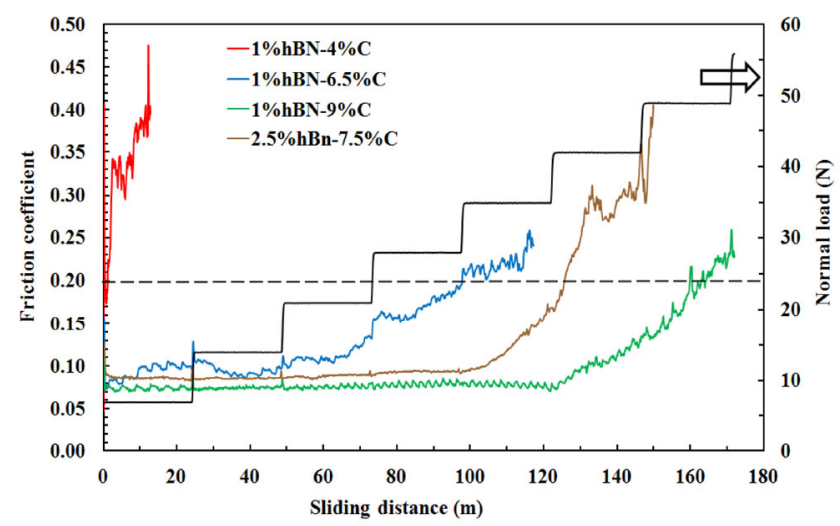

Fig. 18 Evolution of the friction coefficient with the test time, comparing the effect of the total solid lubricant amount $(5,7.5$, and $10 \mathrm{vol} \%$ ) and the effect of the hBN content ( 1 and $2.5 \mathrm{vol} \%$ ). Incremental loading mode [83]. 
solid lubricant content sample ( $1 \mathrm{vol} \% \mathrm{hBN}+4 \mathrm{vol} \%$ C) sharply increased at the very beginning of the test, presenting an almost inexistent lubricious regime.

The same behaviour was exhibited by other composites containing higher percentages of $\mathrm{hBN}$, but a total content solid lubricant equal to $5 \mathrm{vol} \%$ (1.75 vol\% $\mathrm{hBN}+3.25 \mathrm{vol} \% \mathrm{C}$ and $2.5 \mathrm{vol} \% \mathrm{hBN}+2.5 \mathrm{vol} \% \mathrm{C})$. For higher solid lubricant contents, all the specimens behaved in a comparable manner in the lubricious regime. On the other hand, the $7.5 \mathrm{vol} \%$ composite presented a slightly higher friction coefficient and shorter lubricious regime, whereas the $10 \mathrm{vol} \%$ specimens exhibited a longer period in the lubricious regime associated with a steadier and lower friction coefficient. The samples containing $10 \mathrm{vol} \%$ total solid lubricant content clearly exhibited a superior performance, and the best results were obtained when combined with a lower amount of hBN, e.g., $1 \mathrm{vol} \%$.

In general, as the total percentage of solid lubricant increased, a substantial rise in the scuffing resistance was noticed. However, for the three levels of total solid lubricant examined, a decrease in the scuffing resistance was observed as the hBN content increased [83].

The results of the additional scuffing resistance tests conducted and interrupted at $14 \mathrm{~N}$, i.e., within the lubricious regime $(\mu<0.2)$, showed that, typically, solid lubricant reservoirs remained open inside the wear tracks [83]. This, hypothetically, ensured a continuous re-supply of solid lubricant to the contact and, as a consequence, the formation of a tribolayer, which served to continuously maintain the system in the lubricious regime $(\mu<0.2)$. It is reasonable to suppose that the wear debris from the specimens and counter-bodies was continuously comminuted, deformed and reacted with the surrounding atmosphere, forming a protective tribolayer. The tribolayer consisted of a mixture of solid lubricants possessing a lamellar structure that induced lower friction coefficients. The wear scar of the composite with a lower initial solid lubricant amount ( $1 \mathrm{vol} \% \mathrm{hBN}+6.5 \mathrm{vol} \% \mathrm{C}$ ) revealed a degradation of the tribolayer. For the sample $2.5 \mathrm{vol} \%$ $\mathrm{hBN}+7.5 \mathrm{vol} \% \mathrm{C}$, the degradation was at an initial stage, whereas the composite with a higher initial solid lubricant amount ( $1 \mathrm{vol} \% \mathrm{hBN}+9 \mathrm{vol} \% \mathrm{C}$ ) showed no evidence of degradation of the tribolayer, in accordance with the scuffing resistance results [83]. The wear scars on the samples tested at a normal load of $35 \mathrm{~N}$, with a friction coefficient higher than 0.2 , which is beyond the lubricious regime for these conditions, showed a degradation of the tribolayer for all composites [83].

Figure 19 presents the typical Raman spectra obtained in the middle of the wear tracks of the composites, after the scuffing resistance tests were interrupted within the lubricious regime.

Typical microstructural analyses clearly showed three distinct regions, as shown in Fig. 19(a) for the $2.5 \mathrm{vol} \% \mathrm{hBN}+7.5 \mathrm{vol} \% \mathrm{C}$ composite. The black regions (1) correspond to the solid lubricant reservoirs, where characteristic Raman peaks for both hBN and graphite can be observed, as shown in Figs. 19(b) and 19(c). The peak at approximately $1,360 \mathrm{~cm}^{-1}$ (Fig. 19(b)) is attributed to hBN $[90,91]$, whereas the presence of graphite is confirmed by the characteristic peaks in Fig. 19(c), at approximately 1,590 and 2,730 $\mathrm{cm}^{-1}$ [21, 89]. The grey region (2) corresponds to a mixture of the solid lubricants, as observed in Fig. 19(d), which shows the simultaneous presence of graphite and hBN characteristic bands. In this sense, it is reasonable to suppose that this represents a typical tribolayer composition. The lighter region (3) corresponds to the matrix, as shown in Fig. 19(e), in which the spectrum indicates a metallic material and the incipient presence of two small peaks related to carbon and/or hBN indicates their presence. Moreover, at low frequencies, there were low-intensity peaks that can be attributed to the formation of iron oxide by a tribo-chemical reaction with the surrounding atmosphere [94, 95].

The microstructure of the self-lubricating composites used to study the joint effect of solid lubrication in a mixed lubrication regime had two different types of solid lubricant reservoirs regularly distributed in the metallic matrix, whereas, as already indicated, the metallic matrix varied from ferrite + pearlite to martensite (Mo containing alloys) and is well described in a recent paper [9]. As expected, the Mo-rich materials (martensitic) had higher hardness. The addition of solid lubricants did not result in a significant effect on the micro-hardness [9].

Figure 20 illustrates the evolution of the friction coefficient with the sliding distance and position in the stroke under dry conditions. 

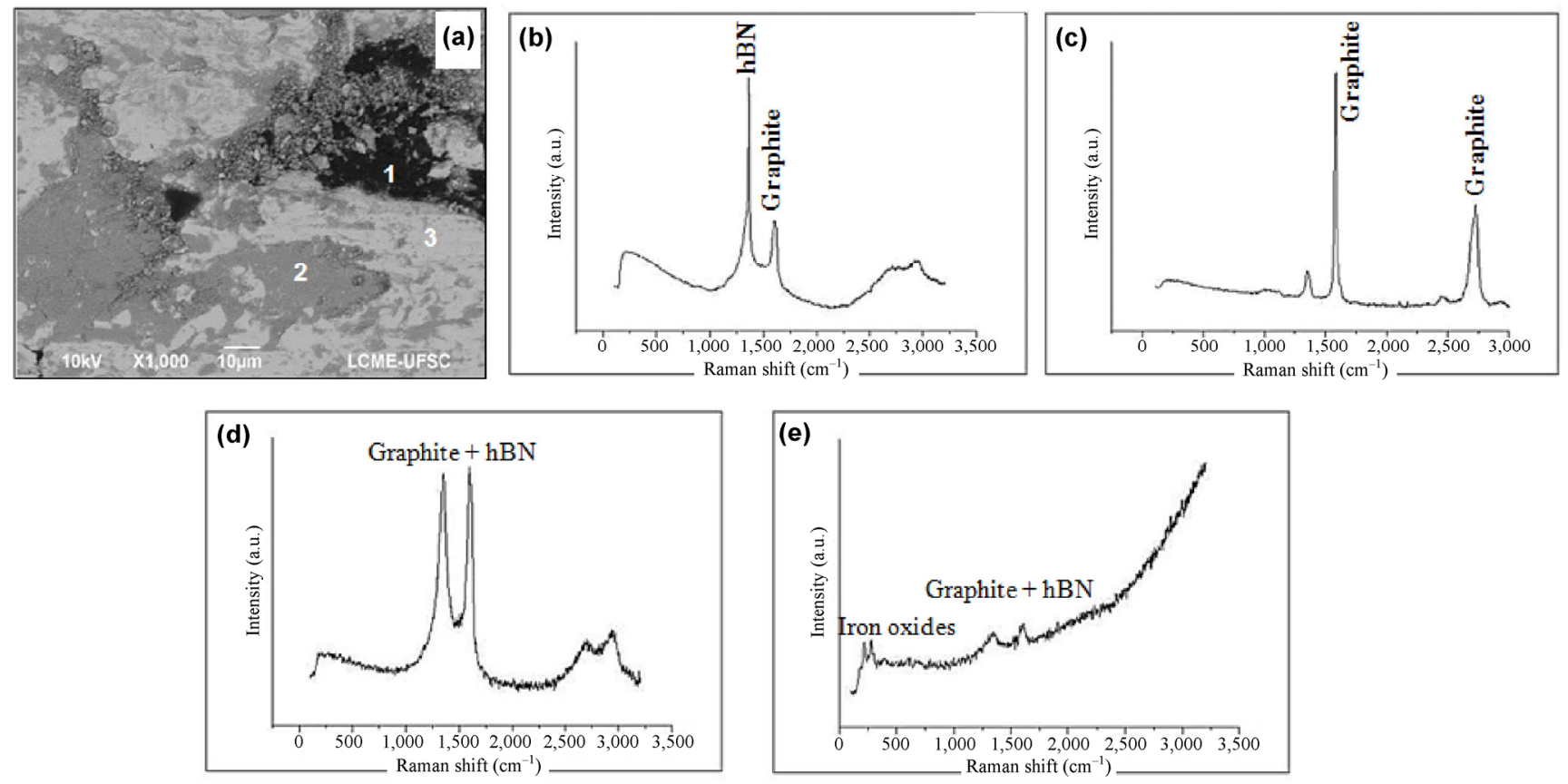

Fig. 19 (a) Typical SEM micrograph of a wear scar within the lubricious regime. Related typical Raman spectra from lubricant reservoirs (region 1, (b) and (c)), tribolayer 2 (region 2, (d)) and metallic substrate (region 3, (e)) [83].
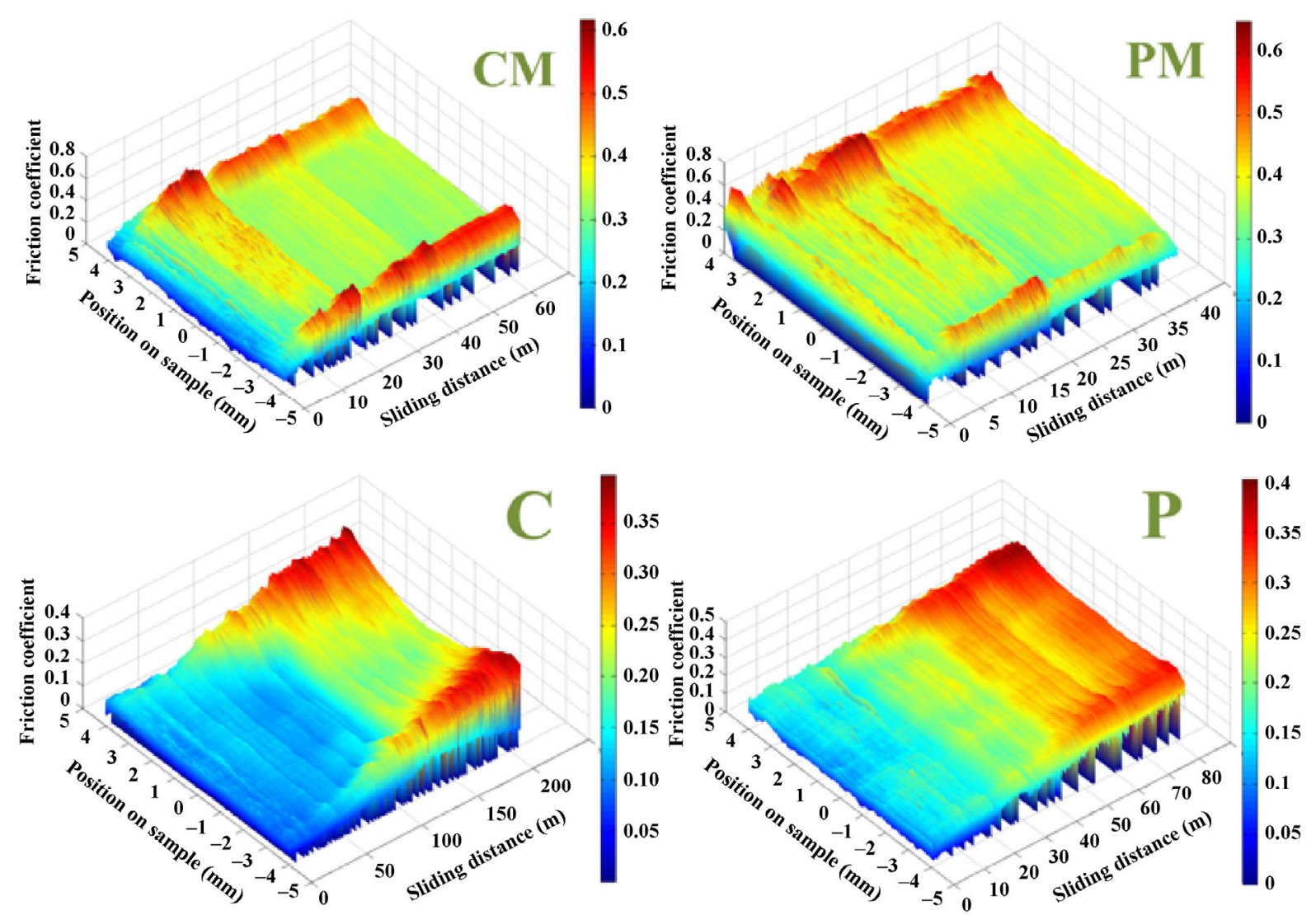

Fig. 20 Typical evolutions of the friction coefficients under dry conditions. Incremental loading mode (increments of $7 \mathrm{~N}$ every $10 \min$ ) [9]. 
For the matrix alloys (CM and $\mathrm{PM})$, the friction coefficient showed a tendency to decrease with an increase in normal load. Additionally, it showed an increase at the dead centres of the movement. This difference between friction coefficients was discussed in terms of debris accumulation and change in the lubrication regime. A preponderant role was assigned to the accumulation of debris [9]. The self-lubricated composites showed a lower friction coefficient in the beginning of the test, and the friction coefficient grew continuously and gently as the test progressed (i.e., the normal force increased). For the P composite, the friction coefficient tended to increase more quickly. Additionally, for the C composite, it presented a marked tendency to increase at the dead centres of the movement.

Figure 21 shows the lubricious regime durability under dry conditions. The solid lubricant addition strongly affected the durability of the lubricious regime. The durability increased by two orders of magnitude for the martensitic samples and an impressive three orders of magnitude for the ferrite-pearlite samples. When the self-lubricating composites were compared, despite its lower hardness (composite C; $\mathrm{HV}=171 \pm$ 57), the ferrite-perlite matrix exhibited a lubricious regime durability (LRD) approximately one order of magnitude larger than the martensitic structure (composite $\mathrm{P} ; \mathrm{HV}=298 \pm 38$ ).

It is reasonable to suppose that the lower hardness of the ferrite-perlite matrix led to higher wear during the lubricious regime, as confirmed by the width of the wear scars presented in Fig. 22 (red arrows) and confirmed by the wear scars profiles [9].

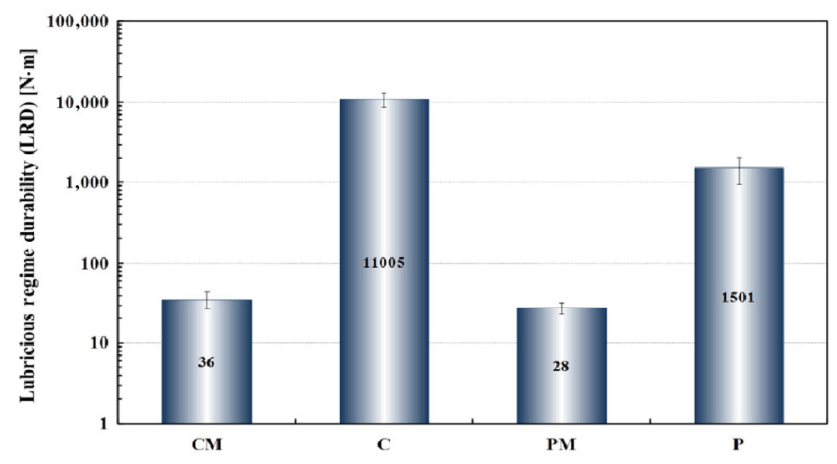

Fig. 21 Lubricious regime durability (LRD) for the dry condition. Incremental loading mode (increments of $7 \mathrm{~N}$ every $10 \mathrm{~min}$ ) [9].
The figure also shows the presence of the active reservoirs of solid lubricants within the wear scars in both samples, as indicated by the green arrows. Higher wear produced a higher amount of wear debris, which, in turn, left the contact richer in solid lubricant. Indeed, the wear scar of composite C (Fig. 22(b)) exhibited a more evident and well-formed tribolayer, shown by the blue arrows, which was much less evident for the case of composite P (Fig. 22(c)). This may result in a low friction coefficient over a longer period, thus increasing the lubricious regime durability. The presence of tribolayers was even less intense for the matrix alloys, probably because of the absence of solid lubricants in the composition of the matrix alloys (Figs. 22(c) and 22(d)).

SEM-EDX analysis showed that the wear scars formed in the self-lubricating composites were quite equivalent in nature, composed mainly of iron and oxygen. Despite the differences in the prevalence of the tribolayers, they indicate the formation of iron oxide by tribochemical reactions caused by the surrounding atmosphere. The solid lubricant reservoirs were composed, as expected, of graphite and hexagonal boron nitride. In addition, the chemical composition of the tribolayers present in the matrix alloys was different from those present in the self-lubricating composites. In fact, analyses by EDX [99] showed that these tribolayers were rich in oxygen, indicating the formation of iron oxide produced by interactions with the surrounding atmosphere. They also had a small amount of chromium, probably from more severe interactions with the counter body (steel AISI 52100).

Figure 23 illustrates the evolution of the friction coefficient with the sliding distance and position in the stroke for the self-lubricated composites in all conditions.

The addition of liquid lubricant to the contact drastically changed the LRD. Indeed, the presence of the lubricant governed the phenomenon. Once again, for the ferrite-pearlite composites, friction coefficient showed a tendency to significantly increase at the dead centres.

Figure 24 compares the LRD for all conditions.

The LRD for the lubricated mode was almost equivalent for all studied materials and was approximately one order of magnitude greater than that 
(a)

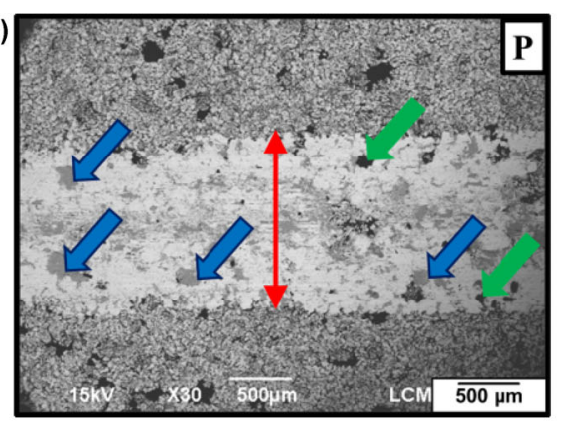

(c)

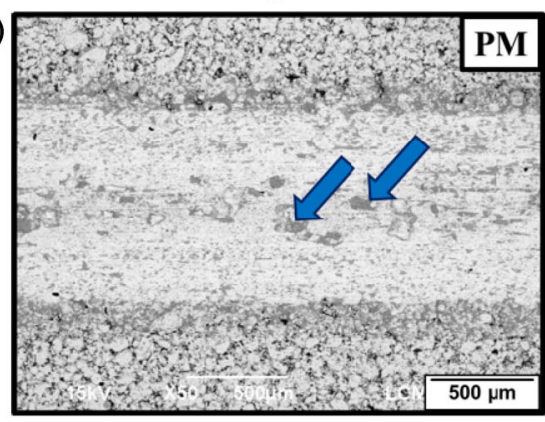

(b)

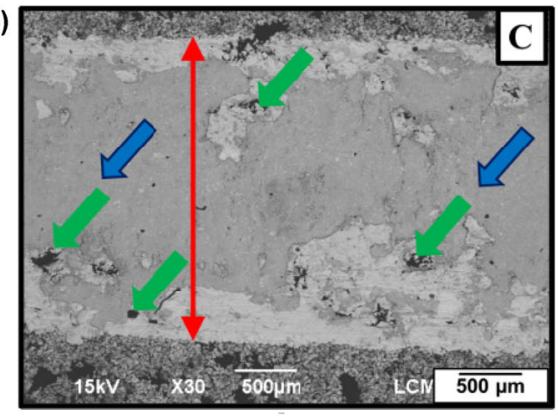

(d)

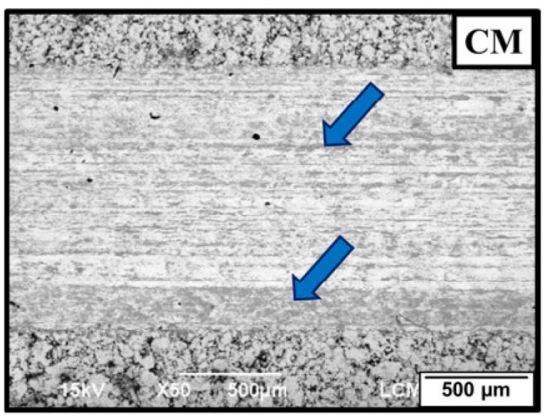

Fig. 22 Typical wear scars. (a) Composite P. (b) Composite C. (c) Alloy PM. (d) Alloy CM. Dry mode [9].
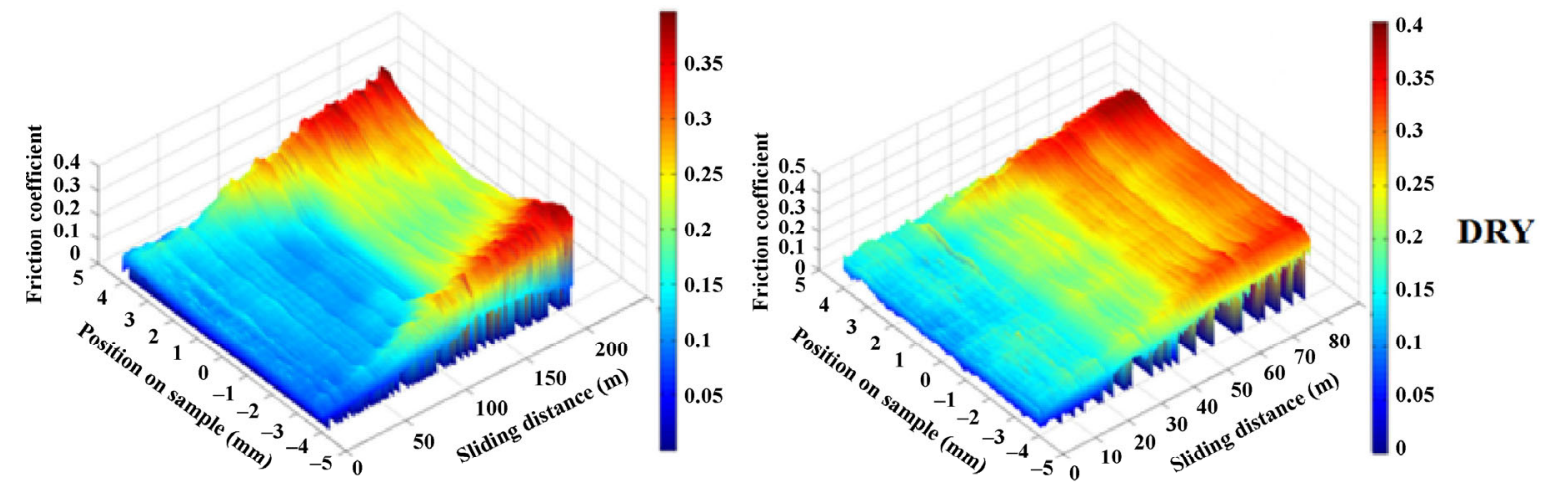

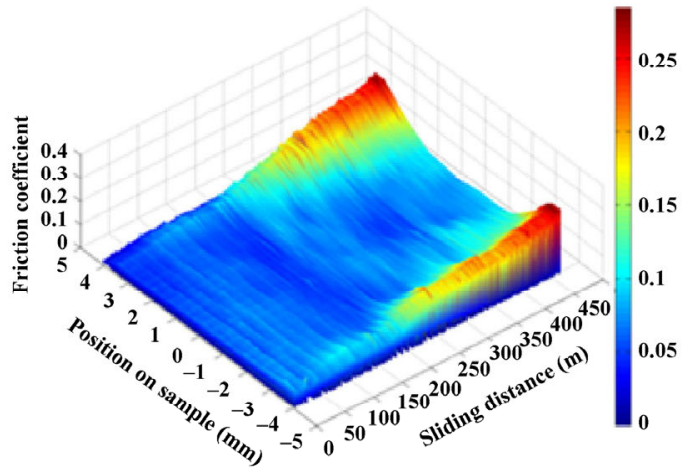

COMPOSITE $\mathrm{C}$

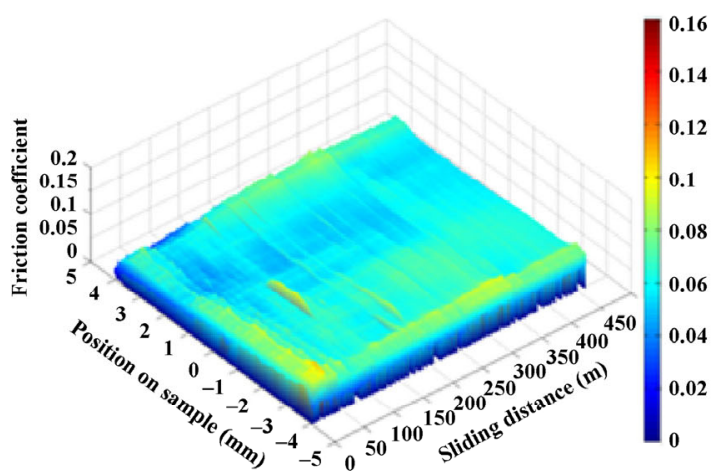

COMPOSITE $\mathbf{P}$

Fig. 23 Typical evolution of the friction coefficient for all conditions. Incremental loading mode (increments of $7 \mathrm{~N}$ every $10 \mathrm{~min}$ ) [9].

of composite $\mathrm{C}$ under dry conditions, two orders of magnitude higher than that of composite $\mathrm{P}$ and three orders of magnitude greater than that of the $\mathrm{CM}$ and PM alloys. 


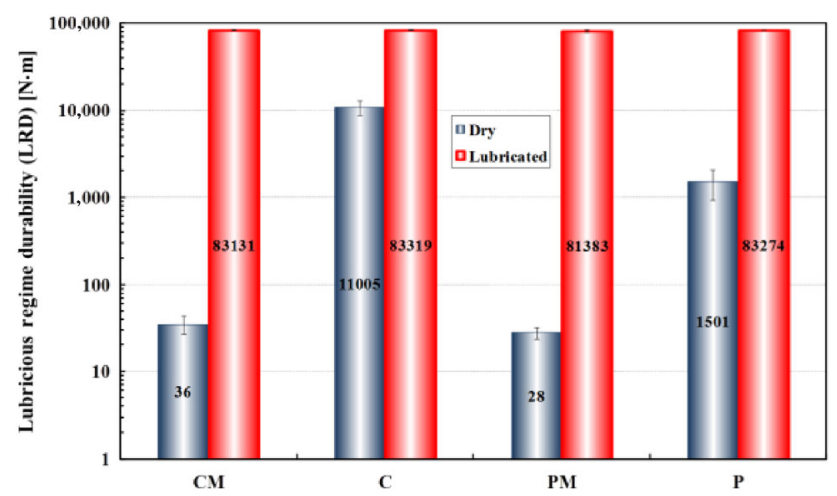

Fig. 24 Lubricious regime durability for all conditions. Incremental loading mode [9].

\section{Concluding remarks}

We present a synthesis of previous works, presenting and discussing the most important results produced by an ongoing research program towards the development of innovative, low-cost, self-lubricating composites with a low friction coefficient associated with high mechanical strength and wear resistance. The results clearly showed the great tailoring capability of the proposed microstructural model/processing routes applied to the development of iron-based selflubricating composites.

Moreover, the optimized processing parameters produced, for all compaction techniques, outstanding new iron-based composites, as illustrated in Table 2.

\section{Acknowledgments}

The authors acknowledge the following Brazilian agencies for funding this research: CNPq, BNDES,

Table 2 Properties of the composites.

\begin{tabular}{ccc}
\hline Property & $\begin{array}{c}\text { Powder injection } \\
\text { moulding }\end{array}$ & $\begin{array}{c}\text { Uniaxial die } \\
\text { pressing }\end{array}$ \\
\hline Scuffing resistance $(\mathrm{N} \cdot \mathrm{m})$ & 8000 & 7580 \\
Friction coefficient & 0.04 & 0.10 \\
$\begin{array}{c}\text { Wear rate specimen } \\
\left(\mathrm{mm}^{3} \cdot \mathrm{N}^{-1} \cdot \mathrm{m}^{-1} \cdot 10^{-6}\right)\end{array}$ & 8.28 & 10.4 \\
$\begin{array}{c}\text { Wear rate counter-body } \\
\left(\mathrm{mm}^{3} \cdot \mathrm{N}^{-1} \cdot \mathrm{m}^{-1} \cdot 10^{-6}\right)\end{array}$ & 9.47 & 37 \\
$\begin{array}{c}\text { Ultimate tensile strength } \\
(\mathrm{MPa})\end{array}$ & 800 & 270 \\
Elongation $(\%)$ & 6.3 & - \\
\hline
\end{tabular}

Capes, Fapesc and Fapemig, as well as Whirlpool/ Embraco. The helpful discussions and valuable suggestions of Prof. Henara Lillian Costa from the Federal University of Rio Grande, Brazil, are also acknowledged.

Open Access: The articles published in this journal are distributed under the terms of the Creative Commons Attribution 4.0 International License (http:// creativecommons.org/licenses/by/4.0/), which permits unrestricted use, distribution, and reproduction in any medium, provided you give appropriate credit to the original author(s) and the source, provide a link to the Creative Commons license, and indicate if changes were made.

\section{References}

[1] Sharma S M, Anand A. Solid lubrication in iron based materials-A Review. Tribology in Industry 38(3): 318-331 (2016)

[2] De Mello J D B, Binder C, Binder R, Klein A N. Effect of precursor content and sintering temperature on the scuffing resistance of sintered self lubricating steel. Wear 271: 1862-1867 (2011)

[3] Cannaday M L, Polycarpou A A. Tribology of unfilled and filled polymeric surfaces in refrigerant environment for compressor application. Tribology Letters 19: 249-262 (2005)

[4] Demas N G, Polycarpou A A. Tribological investigation of cast iron air-conditioning compressor surfaces in $\mathrm{CO}_{2}$ refrigerant. Tribology Letters 22: 271-278 (2006)

[5] Lee Y Z, Oh S D. Friction and wear of the rotary compressor vane-roller surfaces for several sliding conditions. Wear $\mathbf{2 5 5}$ : 1168-1173 (2003)

[6] Solzak T A, Polycarpou A A. Tribology of WC/C coatings for use in oil-less piston-type compressors. Surface \& Coatings Technology 201: 4260-4265 (2006)

[7] Pergande S R, Polycarpou A A, Conry T F. Nanomechanical properties of aluminum 390-T6 rough surfaces undergoing tribological testing. Journal of Tribology-Transactions of the ASME 126: 573-582 (2004)

[8] Bhushan B (Ed.) Modern Tribology Handbook II. New York (USA): CRC Press, 2001.

[9] Oliveira Jr M M, Hammes G, Binder C, Klein A N, de Mello J D B. Solid lubrication in fluid film lubrication. Lubrication Science, Accepted (2017)

[10] Erdemir A. Solid lubricants and self-lubricating films. In Modern Tribology Handbook. Bhushan B Ed. New York 
(USA): CRC Press, 2001.

[11] Myoshi K. Solid lubricants and coatings for extreme environments: State of the art survey. NASA/TM -214668, Ohio, USA, 2007.

[12] Sliney H E. Solid lubricant materials for high temperatures: A review. Tribology International 15: 293-302 (1982)

[13] De Mello J D B, Binder R, Demas N G, Polycarpou A A. Effect of the actual environment present in hermetic compressors on the tribological behaviour of a Si-rich multifunctional DLC coating. Wear 267: 907-915 (2009)

[14] Hammes G, Schroeder R, Binder C, Klein A N, de Mello J D B. Effect of double pressing/double sintering on the sliding wear of self-lubricating sintered composites. Tribology International 70: 119-127 (2014)

[15] de Mello J D B, Binder C, Hammes G, Klein A N. Effect of the metallic matrix on the sliding wear of plasma assisted debinded and sintered MIM self-lubricating steel. Wear 301: 648-655 (2013)

[16] Scharf T W, Prasad S V. Solid lubricants: A review. Journal of Materials Science 48(2): 511-531 (2013)

[17] Katz A, Redlich M, Rapoport L, Wagner H D, Tenne R. Self lubricating coatings containing fullerene-like $\mathrm{WS}_{2}$ nanoparticles for orthodontic wires and other possible medical application. Tribology Letters 21(2): 135-139 (2006)

[18] Donnet C, Erdemir A. Solid lubricant coatings: Recent developments and future trends. Tribology Letters 17(3): 389-397 (2004)

[19] Lancaster J K. Solid lubricants. In CRC Handbook of Lubrication: Theory and Practice of Tribology Vol. II Theory and Design. Booser E R (Ed.). CRC Press, Boca Raton, FL, USA, 1984: 269-290.

[20] Lansdown A R. Molybdenum Disulphide Lubrication. Tribology Series 35. Dowson D (Ed.). Elsevier, Amsterdam, 1999.

[21] Brookes C A, Brookes E J. Diamond on perspective. A review of mechanical properties of natural diamond. Diamond Rel Mater 1: 13-17 (1991)

[22] Donnet C, Erdemir A. Historical developments and new trends in tribological and solid lubricant coatings. Surf Coat Technol 180-181: 76-84 (2004)

[23] Erdemir A. Review of engineered tribological interfaces for improved boundary lubrication. Tribol Int 38: 249-256 (2005)

[24] Pauleau Y, Thièry F. Deposition and characterization of nanostructured metal/carbon composite films. Surf Coat Tech 180-181: 313-322 (2004)

[25] Xiong D. Lubrication behavior of Ni-Cr-based alloys containing $\mathrm{MoS}_{2}$ at high temperature. Wear 251: 1094-1099
(2001)

[26] Kimura Y, Wakabayashi T, Okada K, Wada T, Nishikawa H. Boron nitride as a lubricant additive. Wear 232: 199-206 (1999).

[27] Mosleh M, Atnafu N D, Belk J H, Nobles O M. Modification of sheet metal forming fluids with dispersed nanoparticles for improved lubrication. Wear 267(5-8): 1220-1225 (2009)

[28] Rapoport L, Feldman Y, Homyonfer M, Cohen H, Sloan J, Hutchison J L, Tenne R. Inorganic fullerene-like material as additives to lubricants: structure-function relationship. Wear 225-229: 975-982 (1999)

[29] Joly-Pottuz L, Dassenoy F, Belin M, Vacher B, Martin J M, Fleischer N. Ultralow-friction and wear properties of IF-WS2 under boundary lubrication. Tribology Letters 18(4): 477-485 (2005)

[30] Tontini G, Semione G D, Bernardi L C, Binder R, de Mello J D B, Drago V. Synthesis of nanostructured flower-like $\mathrm{MoS}_{2}$ and its friction properties as additive in lubricating oils. Industrial Lubrication and Tribology 68(6): 658-664 (2016)

[31] Hernández Battez A, González R, Viesca J L, Fernández J E, Díaz Fernández J M, Machado A, Chou R, Riba J. CuO $\mathrm{ZrO}_{2}$ and $\mathrm{ZnO}$ nanoparticles as antiwear additive in oil lubricants. Wear 265(3-4): 422-428 (2008)

[32] Wu Y Y, Tsui W C, Liu T C. Experimental analysis of tribological properties of lubricating oils with nanoparticle additives. Wear 262(7-8): 819-825 (2007)

[33] Hu Z S, Dong J X. Study on antiwear and reducing friction additive of nanometer titanium borate. Wear 216(1): 87-91 (1998)

[34] Pacheco F G, Oliveira Jr M M, Santos A P, Costa H L, de Mello J D B, Furtado C A. Tribological evaluation of carbon nanotubes as additives in palm biolubricants. Submitted to Lubricants (2017)

[35] Eswaraiah V, Sankaranarayanan V, Ramaprabhu S. Graphenebased engine oil nanofluids for tribological applications. ACS Applied Materials Interfaces 3(11): 4221-4227 (2011)

[36] Fan X, Wang L. High-performance lubricant additives based on modified graphene oxide by ionic liquids. Journal of Colloid and Interface Science 452: 98-108 (2015)

[37] Choudhary S, Mungse H P, Khatri O P. Dispersion of alkylated graphene in organic solvents and its potential for lubrication applications. Journal of Materials Chemistry 22(39): 21032 (2012)

[38] Zhang W, Zhou M, Zhu H, Tian Y, Wang K, Wei J, Ji F, Li X, Li Z, Zhang P, Wu D. Tribological properties of oleic acid-modified graphene as lubricant oil additives. Journal of Physics D: Applied Physics 44(20): 205303 (2011)

[39] Burri D L, Sawyer W G. A low friction and ultra-low wear 
rate PEEK/PTFE composite. Wear 261: 410-418 (2006)

[40] Ouyang J H. Microstructure and tribological properties of $\mathrm{ZrO}_{2}\left(\mathrm{Y}_{2} \mathrm{O}_{3}\right)$ matrix composites doped with different solid lubricants from room temperature to $800{ }^{\circ} \mathrm{C}$. Wear 267: 1353-1360 (2009)

[41] Chen B, Bi Q, Yang J, Xia Y, Hao J. Tribological properties of solid lubricants (graphite h-BN) for Cu-based $\mathrm{P} / \mathrm{M}$ friction composites. Tribol Int 41: 1145-1152 (2008)

[42] Moghadam A D, Omrani E, Menezes P L, Rohatgi P K. Mechanical and tribological properties of self-lubricating metal matrix nanocomposites reinforced by carbon nanotubes (CNTs) and graphene: A review. Composites Part B Engineering 77: 402-420 (2015)

[43] Tsuya Y, Shimura H, Umeda K. A study of the properties of copper and copper-tin base self-lubricating composites. Wear 22: 143-162 (1972)

[44] Liu E R, Wang W, Gao Y, Jia J. Tribological properties of Ni-based self-lubricating composites with addition of silver and molybdenum disulfide. Tribology International 57: 235-241 (2013)

[45] Binder C, Hammes G, Schroeder R M, Klein A N, de Mello J D B, Binder R. Fine tuned steels point the way to focused future. Metal Powder Report 65: 29-37 (2010)

[46] Mahathanabodee S, Palathai T, Raadnui S, Tongsri R, Sombatsompop N. Effects of hexagonal boron nitride and sintering temperature on mechanical and tribological properties of SS316L/h-BN composites. Materials \& Design 46: 588-597 (2013)

[47] Teisanu C, Gheorghe S. Development of New PM IronBased Materials for Self-Lubricating Bearings. Advances in Tribology 2011: 248037 (2011)

[48] Campos K R, Kapsa P, Binder C, Klein A N, de Mello J D B. Tribological Evaluation of Self-lubricating Sintered Steels. Wear 332: 932-940 (2015)

[49] Schroeder R, Klein A N, Binder C, de Mello J D B. Internal lubricant as an alternative to coating steels. Met Powder Rep 65(7): 24-31 (2010)

[50] Ünlü B S. Tribological and Mechanical Properties of PM Journal Bearings. Powder Metal 54(3): 338-342 (2011)

[51] Merie V V, Candea V C, Popa C O. The influence of nickel content on the properties of fe-based friction composite materials. Metal Int 16(4): 93-96 (2011)

[52] Yilmaz S S, Ünlü B S, Varol R. Effect of boronizing and shot peening in ferrous based $\mathrm{FeCu}$-graphite powder metallurgy material on wear microstructure and mechanical properties. Mater Des 31(9): 4496-4501 (2010)

[53] Dhanasekaran S, Gnanamoorthy R. Microstructure strength and tribological behavior of $\mathrm{Fe}-\mathrm{C}-\mathrm{Cu}-\mathrm{Ni}$ sintered steels prepared with $\mathrm{MoS}_{2}$ addition. J Mater Sci 42(12): 4659-4666 (2007)

[54] De Mello J D B, Binder R, Klein A N, Hutchings I M. Effect of compaction pressure and powder grade on microstructure and hardness of steam oxidised sintered iron. Powder Metall 441: 53-61 (2001)

[55] De Mello J D B, Hutchings I M. Effect of processing parameters on the surface durability of steam-oxidized sintered iron. Wear 250: 435-448 (2001)

[56] Lim S C, Brunton H. The unlubricated wear of iron. Wear 113: 371-382 (1986)

[57] Simchi A, Danninger H. Effects of porosity on delamination wear behaviour of sintered plain iron. Powder Metallurgy 47: 73-80 (2004)

[58] Ahn H S, Kim J Y, Lim D S. Tribological behaviour of plasma-sprayed zirconia. Wear 203: 77-87 (1997)

[59] Chen Q, Li D Y, Cook B. Is porosity always detrimental to the wear resistance of materials?-A computational study on the effect of porosity on erosive wear of $\mathrm{TiC} / \mathrm{Cu}$ composites. Wear 267(5-8): 1153-1159 (2009)

[60] Dubrujeaud B, Vardavoulias M, Jeandin M. The role of porosity in the dry sliding wear of a sintered ferrous alloy. Wear 174(1-2): 155-161 (1994)

[61] Huang C, Du L, Zhang W. Effects of solid lubricant content on the microstructure and properties of $\mathrm{NiCr} / \mathrm{Cr}_{3} \mathrm{C}_{2}-\mathrm{BaF}_{2} \cdot \mathrm{CaF}_{2}$ composite coatings. Journal of Alloys and Compounds 479: 777-784 (2009)

[62] Zhu S, Bi Q, Yang J, Liu W, Xue Q. Effect of particle size on tribological behaviour of $\mathrm{Ni}_{3} \mathrm{Al}$ matrix high temperature self-lubricating composites. Tribology International 44: 1800-1809 (2011)

[63] Reeves C J, Menezes P L, Lovell M R, Jen T C. The influence of surface roughness and particulate size on the tribological performance of bio-based multi-functional hybrid lubricants. Tribology International 88: 40-55 (2015)

[64] Zhang D, Lin P, Dong G, Zen Q. Mechanical and tribological properties of self-lubricating laminated composites with flexible design. Materials \& Design 50: 830-838 (2013)

[65] Xu Z, Zhang Q, Huang X, Liu R, Zhai W, Yang K, Zhu Q. An approximate model for the migration of solid lubricant on metal matrix self-lubricant composites. Tribology International 93: 104-114 (2016)

[66] Alexeyev N, Jahanmir S. Mechanics of friction in self lubricating composite materials I: Mechanics of second phase deformation and motion. Wear 166: 41-48 (1993)

[67] Alexeyev N, Jahanmir S. Mechanics of friction in self lubricating composite materials II: Deformation of the interfacial film. Wear 166: 49-54 (1993) 
[68] Binder C, Bendo T, Hammes G, Neves G O, Binder R, de Mello J D B, Klein A N. Structure and properties of in situgenerated two-dimensional turbostratic graphite nodules. Carbon, Accepted (2017)

[69] Metal Powder Industries Federation. Conventional Powdered Metal Component. Princeton (USA): PM Design Center, 2012.

[70] Tamura S, Aizawa T, Mitzuno T, Kihara J. Steel powder compaction analysis. International Journal of Powder Metallurgy 34: 50-59 (1998)

[71] Al-Qureshi H A, Galiotto A, Klein A N. On the mechanics of cold die compaction for powder metallurgy. Journal of Materials Processing Technology 166: 135-143 (2005)

[72] Pavanati H C, Maliska A M, Klein A N, Muzart J L R. Comparative study of porosity and pores morphology of unalloyed iron sintered in furnace and plasma reactor. Materials Research 10(1): 87-93 (2007).

[73] Milligan D, Engstrom U, Lingenfelter J, Dizdar S, Nyberg I. Materials properties of heat treated double pressed/sintered $\mathrm{P} / \mathrm{M}$ steels in comparison to warm compacted/sinter hardened materials. SAE Technical Paper 2003-01-0338 (2003)

[74] James W B, Causton R J, Fulmer J J. Optimized double press-double sinter powder metallurgy method. US Patent 5080712, 1992.

[75] Machado R, Ristow Jr W, Klein A N, Muzart J L R, Fredel M C, Wendhausen P A P, Fusão D, Alba P R, da Silva N F O, Mendes L A. Industrial Plasma reactor for plasma assisted thermal debinding of powder injection molded parts. US Patent US7718919B2 PCT (WO 2006012718) and INPI (PI-0403536-4), 2010.

[76] Wendhausen P A P, Fusao D, Klein A N, Muzart J L R, Ristow Jr W, Machado R. Plasma assisted debinding and sintering: process and equipment. In Proceeding of the Powder Metallurgy World Congress \& Exhibition EURO PM2004, 2004: 37-142.

[77] Klein A N, Muzart J L R, Souza A R, Fredel M C, Wendhausen P A P. Process for removal of binders from parts produced by powder injection moulding. US patent US 6579493 B1, 2003.

[78] Klein A N, Binder C, Hammes G, de Mello J D B, Ristow W, Binder R. Self lubricating sintered steels with high mechanical resistance obtained via in situ formation of solid lubricant particles during sintering. In Proceedings of EURO PM2009, 2009: 191-196.

[79] Binder R, Klein A N, Binder C, Hammes G, Parucker M L, Ristow Jr W. Composição metalúrgica de materiais particulados produto sinterizado autolubrificante e processo de obtenção de produtos sinterizados autolubrificantes. Patent application PI 0803956-9 INPI, Brazil, 2008.
[80] Binder R, Binder C, Ristow Jr W, Klein A N. Composition of particulate materials for forming self-lubricating products in sintered steels product in self- lubricating sintered steel and process for obtaining self-lubricating products in sintered steel. PI0805606-Brazil; US 20110286873A1-USA; International Number: WO 2010/069020 A2-Europe; CN102497948AChina; JP 2012-512320-Japan; 10-2011-0110179-South Korea; SG 172168 A1-Singapore TW 201034773 A1-Taiwan, 2008.

[81] Binder C. Desenvolvimento de novos tipos de aços sinterizados autolubrificantes a seco com elevada resistência mecânica aliada a baixo coeficiente de atrito via moldagem de pós por injeção. (In Portuguese). Ph. D Thesis. Florianópolis (Brazil) Federal University of Santa Catarina, 2009.

[82] Campos K R, Kapsa P, Binder C, Klein A N, de Mello J D B. Influence of surface finishing on the tribological behaviour of self-lubricating iron based composites. Tribology Transactions, Accepted (2017)

[83] Hammes G, Mucelin K J, Gonçalves P C, Binder C, Binder R, Janssen R, Klein A N, de Mello J D B. Effect of hexagonal boron nitride and graphite on mechanical and scuffing resistance of self lubricating iron based composite. Wear 376-377: 1084-1090 (2017)

[84] Metal Powder Industries Federation. Standard test methods for metal powders and powder metallurgy products. 2012: $37-42$.

[85] de Mello J D B, Binder R. A methodology to determine surface durability in multifunctional coatings applied to soft substrates. Tribology international 39: 769-773 (2006)

[86] dos Santos M B, Costa H L, de Mello J D B. Potentiality of triboscopy to monitor friction and wear. Wear 332-333: 1134-1144 (2015)

[87] Fontaine J, Bein M, Le Mogne T, Grill A. How to restore superlow friction of DLC: The healing effect of hydrogen gas. Tribology International 37: 869-877 (2004)

[88] Ferrari A C, Robertson J. Resonant Raman spectroscopy of disordered amorphous and diamond like carbon. Phys Rev $B$ 64: 075414 (2001)

[89] Robertson J. Diamond-like amorphous carbon. Mater Sci Eng R37: 129-281 (2002)

[90] Zhang W J, Chong Y M, Bello I, Lee S T. Nucleation growth and characterization of cubic boron nitride (cBN) films. J Phys D Appl Phys 40: 6159-6174 (2007)

[91] Arenal R, Ferrari A C, Reich S, Wirtz L, Mevellec J-Y, Lefrant S, Rubio A, Loiseau A. Raman spectroscopy of single-wall boron nitride nanotubes. Nano Lett 6(8): 1812 1816 (2006)

[92] de Faria D L A, Venâncio S S, de Oliveira M T. Raman microspectroscopy of some iron oxides and oxyhydroxides. 
J Raman Spectrosc 28: 873-878 (1997)

[93] Oh S J, Cook D C, Townsend H E. Characterization of iron oxides commonly formed as corrosion product on steel. Hyperfine Interactions 112: 59-65 (1998)

[94] Crockett R M, Derendinger M P, Hug P L, Roos S. Wear and electrical resistance on diesel lubricated surfaces undergoing reciprocating sliding. Tribology Letters 16: 187-194 (2004)

[95] Ouyang M, Hiraoka H. Structure and magnetic properties of iron oxide films deposited by excimer laser ablation of a metal-containing polymer Materials. Research Bulletin 32: 1099-1107 (1997)
[96] German R M. Powder Metallurgy And Particulate Materials Processing. $1^{\text {st }}$ ed. Princeton New Jersey Metal Powder Industries Federation, 2005.

[97] Hammes G, Gonçalves P, Binder C, Furlan K P, Klein A N. Fe-hBN Composites produced by double pressing and double sintering. Mater Sci Forum 802: 311-316 (2014)

[98] Smith W F. Structure and Properties of Engineering Alloys. New York (USA): Mc Graw-Hill, 1993.

[99] Oliveira Jr M M. Lubrificação sólida em meio fluído. (In Portuguese). M. Sc. Dissertation. Universidade Federal de Uberlândia Uberlândia Brazil, 2013.

1998-1999, he worked as a visiting scholar at the Department of Materials Science and Metallurgy, University of Cambridge, UK. In 2007 he worked as a Fulbright visiting professor at the University of Illinois at Urbana-Champaign, USA. He is a member of the editorial board of several journals including Friction. Professor De Mello has published more than 300 full papers in proceedings of national and internationals conferences, congresses and journals. Professor De Mello's current researches are abrasioncorrosion, surface durability of solid lubricants, and tribological behaviour of sintered material.

materials science and engineering from the Federal University of Santa Catarina (2009). He is currently a professor at the Federal University of Santa Catarina. He has experience in the field of materials engineering, focusing on plasma materials processing, powder metallurgy, and surface engineering. He authored/

co-authored 42 research papers and holds 15 patents. of Santa Catarina (2006) and the PhD degree in

Cristiano BINDER. He received the bachelor degree in chemical engineering from the Federal University of Santa Catarina (2004), the master degree in materials science and engineering from the Federal University 


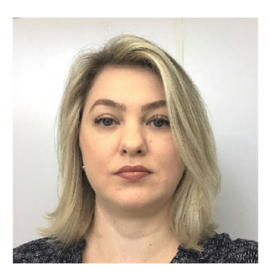

Gisele HAMMES. She received her bachelor degree in materials engineering from the Federal University of Santa Catarina (2004), and her MS and PhD degrees in materials science and engineering

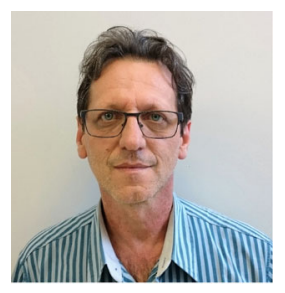

Roberto BINDER. He received the degree in mechanical engineering from the Federal University of Santa Catarina (1993) and the master degree in materials science and engineering from the Federal University of Santa Catarina (1996). He is currently a senior researcher at the Brazilian Compressors Company (EMBRACO), where he has been working since 1998. He is a corporate specialist in engineering

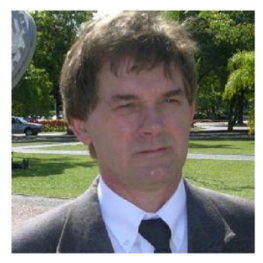

Aloisio Nelmo KLEIN. He received his B.S. degree in physics (1976) and his master degree in materials engineering (1979) from Federal University of Rio Grande do Sul (Brazil) and his PhD. degree from University of Karlsruhe (Germany) in 1983. He is a full professor at the Mechanical Engineering Department, Federal University of Santa Catarina where he works since 1983. Professor Klein has published more than from the Federal University of Santa Catarina in 2006 and 2011, respectively. She is currently a postdoctoral researcher at Materials Laboratory at this university, working with self-lubricating materials, soft magnetic materials, and surface engineering. She has published 18 papers and holds 4 patents.

and materials science, acting as coordinator of research projects in partnerships with universities and research institutes, activities that aim to overcome the state of the art materials solutions for refrigeration compressors. He has experience in powder metallurgy and surface treatments, working mainly on the following topics: iron and sintered steel, solid lubricants, plasma nitriding, DLC coatings, tribology, and materials characterization techniques.

340 full papers in proceedings of national and internationals conferences, congresses, and journals. He also holds 123 national and international patents. $\mathrm{He}$ is the head of the Laboratory of Materials (LabMat/UFSC) since 1984. He led the creation of the postgraduate course in materials science and engineering (master's and doctorate) at UFSC (1994) and the creation of the undergraduate course in Materials Engineering UFSC (1997 to 1999). 